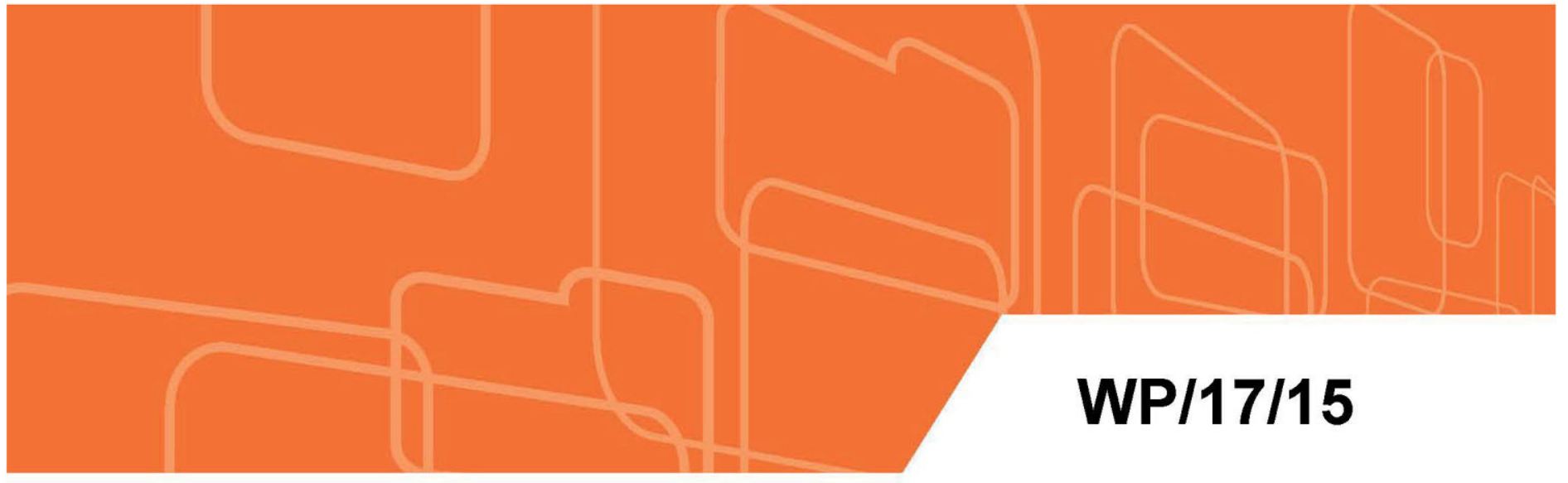

IMF Working Paper

\title{
Oil Prices and the Global Economy
}

by Rabah Arezki, Zoltan Jakab, Douglas Laxton, Akito Matsumoto, Armen Nurbekyan, Hou Wang, and Jiaxiong Yao 


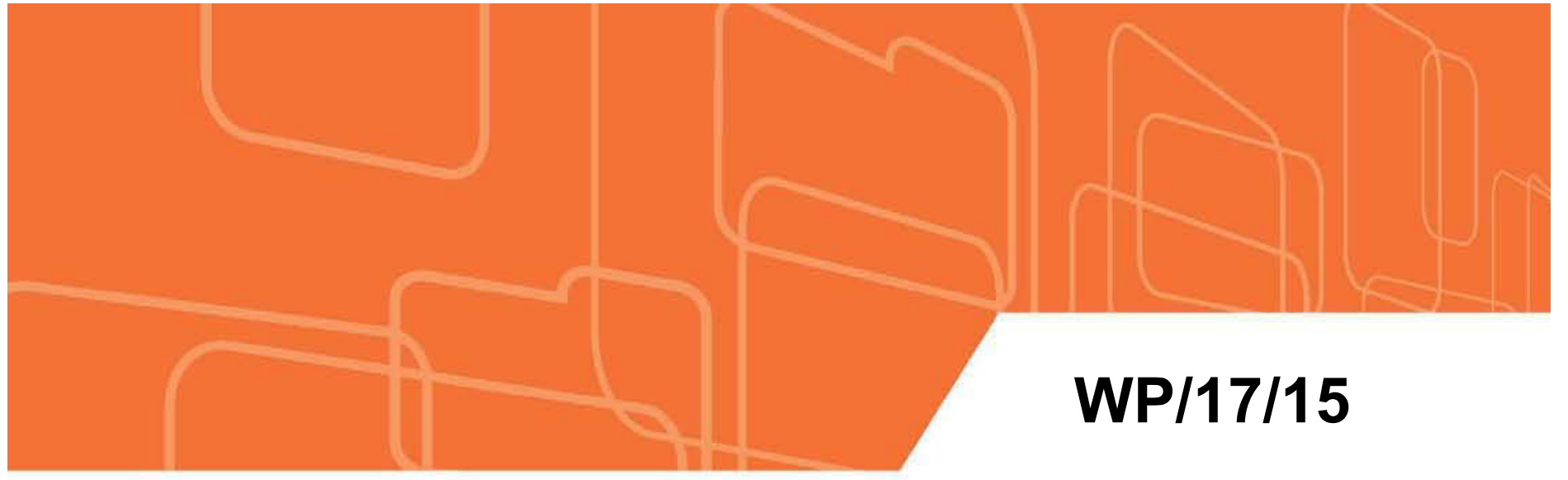

\section{IMF Working Paper}

\section{Oil Prices and the Global Economy}

by Rabah Arezki, Zoltan Jakab, Douglas Laxton, Akito Matsumoto, Armen Nurbekyan, Hou Wang, and Jiaxiong Yao

I N T ER N A T I O N A L M O N E T A R Y FU N D 


\title{
IMF Working Paper
}

\author{
Research Department
}

\section{Oil Prices and the Global Economy}

\author{
Prepared by Rabah Arezki, Zoltan Jakab, Douglas Laxton, \\ Akito Matsumoto, Armen Nurbekyan, Hou Wang, and Jiaxiong Yao*
}

January 2017

\section{IMF Working Papers describe research in progress by the author(s) and are published to elicit comments and to encourage debate. The views expressed in IMF Working Papers are those of the author(s) and do not necessarily represent the views of the IMF, its Executive Board, or IMF management.}

\begin{abstract}
This paper presents a simple macroeconomic model of the oil market. The model incorporates features of oil supply such as depletion, endogenous oil exploration and extraction, as well as features of oil demand such as the secular increase in demand from emerging-market economies, usage efficiency, and endogenous demand responses. The model provides, inter alia, a useful analytical framework to explore the effects of: a change in world GDP growth; a change in the efficiency of oil usage; and a change in the supply of oil. Notwithstanding that shale oil production today is more responsive to prices than conventional oil, our analysis suggests that an era of prolonged low oil prices is likely to be followed by a period where oil prices overshoot their long-term upward trend.
\end{abstract}

JEL Classification Numbers: C11, C53, Q31, Q32

Keywords: Oil market; macroeconomic model; depletion; consumption efficiency; technology; cycle.

Author's E-Mail Address: RArezki@imf.org; ZJakab@,imf.org; DLaxton@imf.org; AMatsumoto@imf.org; Armen.Nurbekyan@cba.am; HWang2@imf.org; JYao@,imf.org

*We are grateful to Oliver Blanchard, Gian Maria Milesi-Ferretti, Aasim Husain, Maurice Obstfeld, and colleagues from the oil group and participants in the Stanford Institute for Economic Policy Research Economic Summit 2015 for very useful comments and suggestions. We thank Rachel Yuting Fan for outstanding research assistance. The views expressed in this paper are those of the authors and do not necessarily reflect those of the International Monetary Fund, its Board of Directors or the countries they represent. All remaining errors are ours. 


\section{Table of Contents}

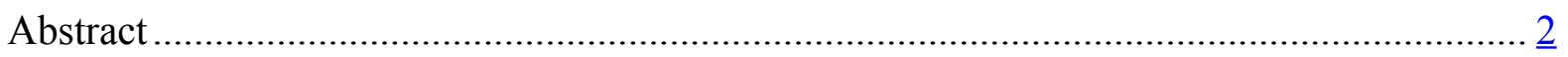

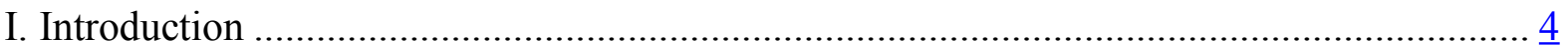

II. The Prevailing "Views" in Existing Models of the Oil Market ...................................... 7

III. An Integrated Model of Supply and Demand .................................................... 14

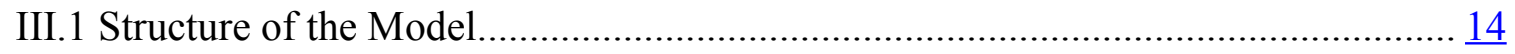

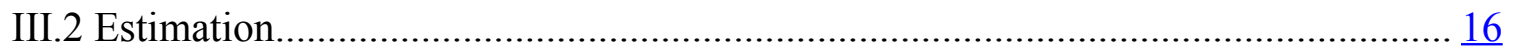

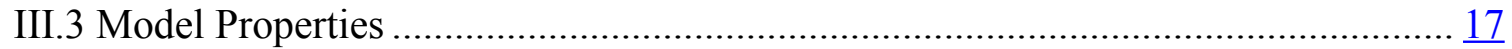

IV. Illustrative Model Simulations ............................................................................ 21

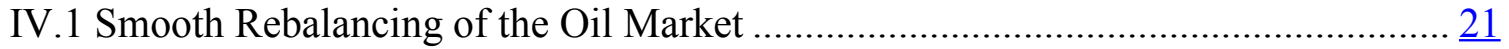

IV.2 Alternative Scenarios ............................................................................. 22

World GDP Growth Scenarios .................................................................. 22

Consumption Efficiency Scenarios …..................................................... 22

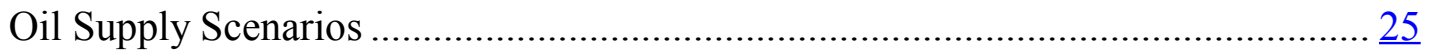

V. The Risk of Oil Price Overshooting......................................................................... 27

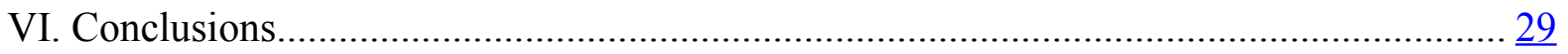

\section{Tables}

Table 1. World Oil Production by Type in the New Policies Scenario ................................ 7

Table 2. Projected World Oil Production ......................................................................

Table 3. Parameter Estimates.......................................................................................... 18

Table 4. Model Root Mean Squared Errors Compared to Benchmark Forecasts....................29

\section{Figures}

Figure 1. West Texas Intermediate (WTI) and Brent Oil Prices ........................................ 4

Figure 2. EIA Forecasts versus Colin Campbell Forecasts, 2003-2011 …............................ $\underline{5}$

Figure 3. Unconventional Oil Investment and Production .............................................. $\underline{8}$

Figure 4. Illustrative Oil Supply "Break-Even” Cost Curve as of December, 2015 ................

Figure 5. Oil Prices and OPEC Spare Capacity ….................................................... 10

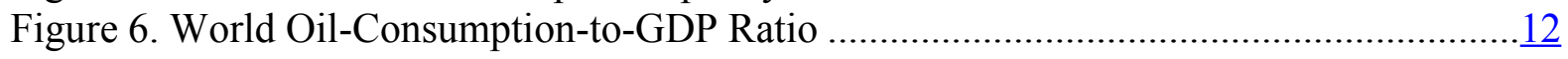

Figure 7. Fuel Economy of New Cars in the U.S. ..................................................... 12

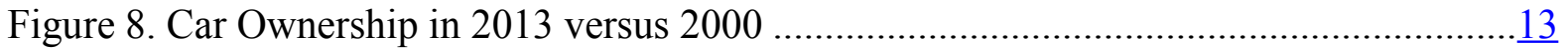

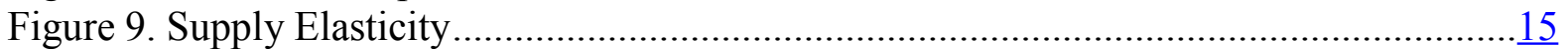

Figure 10. Impulse Response Functions ...............................................................20

Figure 11. Scenario of Smooth Rebalancing of the Oil Market ........................................ 22

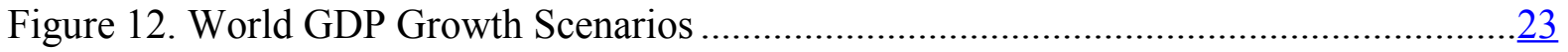

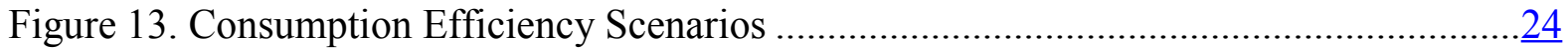

Figure 14. Oil Supply Scenarios ............................................................................... 26

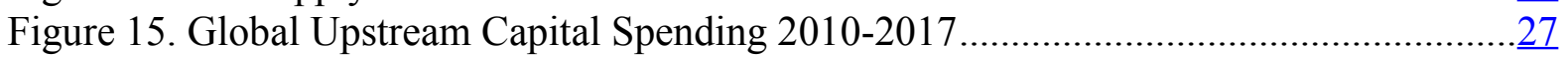

Figure 16. The Risk of Oil Price Overshooting ........................................................ 


\section{INTRODUCTION}

Oil prices have more than halved since June 2014, taking most analysts by surprise (see Figure 1). Since then, much has been written about what triggered the slump, and specifically about the relative role of supply and demand factors (see Arezki and Blanchard, 2014; Obstfeld, Milesi-Ferretti, and Arezki, 2016; Chapter 1 in the April 2016 World Economic Outlook). When demand and supply price elasticities are low, disturbances on either side of the market can result in sharp price fluctuations. Indeed, the oil market experienced large shocks during this period. Demand was affected by negative revisions to global economic prospects. Supply disturbances had numerous sources: armed conflict; new discoveries and extraction technologies; strategic shifts on the part of the Organization of the Petroleum Exporting Countries (OPEC); and so on. While these disturbances played out within an environment where short-run demand elasticities in the oil market were very low, such conditions are unlikely to persist over the medium term given the development of alternative technologies based on natural gas and electric-powered transportation. In this paper, we use a simple macroeconomic model of the oil market to show the implications of higher longerterm demand and supply elasticities. The important insight is that the short-term behavior of oil prices is not necessarily a good guide to their longer-term behavior.

Figure 1. West Texas Intermediate (WTI) and Brent Oil Prices (in current U.S. dollars per barrel)

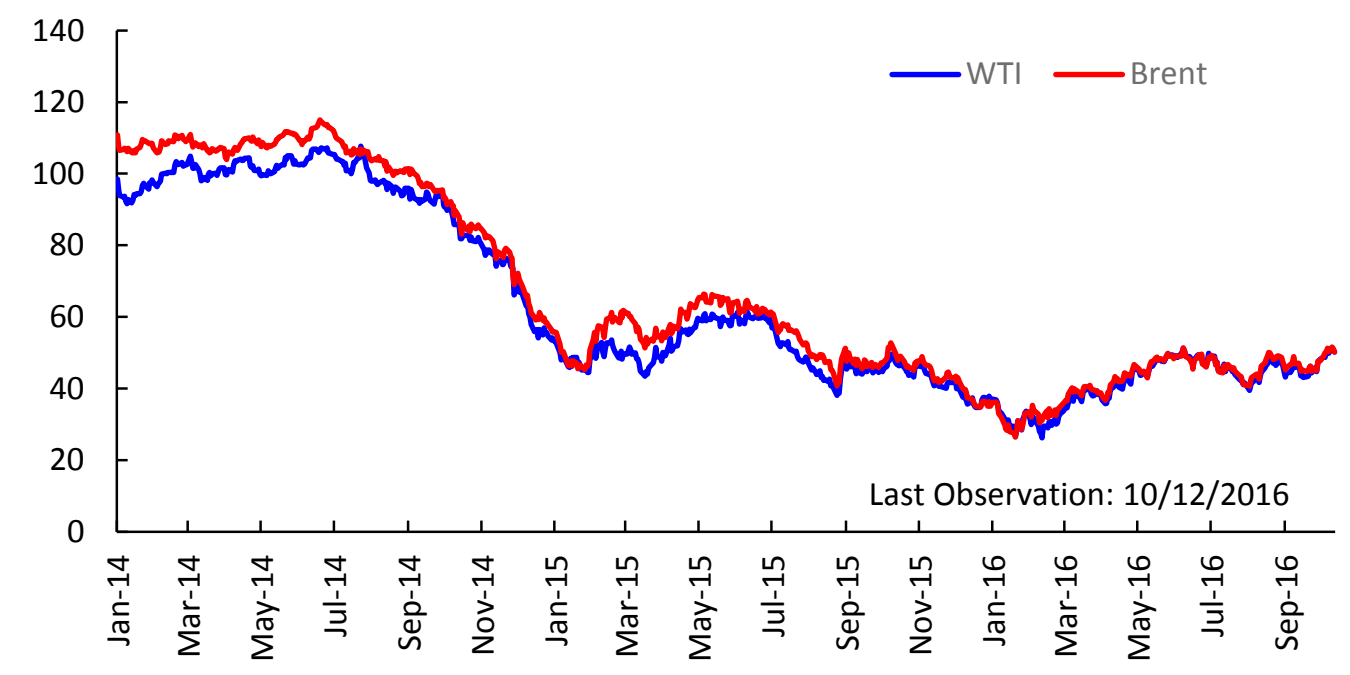

Source: Bloomberg L.P.

Existing models that extrapolate short-term trends in the oil market have important limitations. They typically reflect one of two competing views about future supply. The socalled "peak oil" view emphasizes geological constraints. A peak in production was predicted in the early 2000s. That view promoted by petroleum geologist Colin Campbell, turned out to be overly pessimistic (see Figure 2). Oil production has indeed continued to grow, including as a result of the increased exploitation of shale oil and oil sands in North 
America. The competing view, the so-called "technology view" which predicts that technology will bring production up to the level demanded without much price increase, proved to be overly optimistic. That is exemplified by the successive downward revisions to global oil production from the Energy Intelligence Administration (see Figure 2). This prediction missed the post-2003 surge in prices that resulted from fast-growing demand in emerging markets, especially China. It is thus high time to integrate supply and demand in a more transparent model-based framework and to endogenize factors that may appear constant in the short run but will likely change over time in response to price incentives or changes in technology.

Figure 2. EIA Forecasts versus Colin Campbell Forecasts, 2003-2011 (in millions of barrels per day)

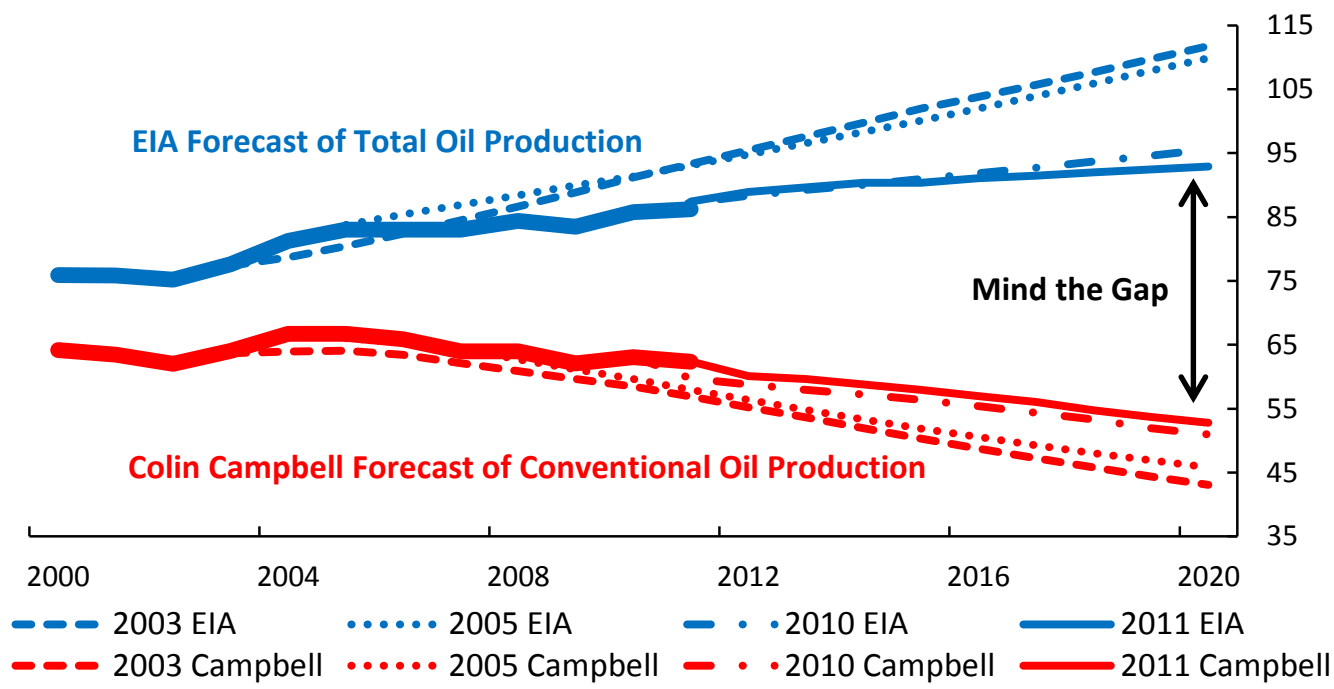

Note: EIA total oil supply definition includes crude oil (including lease condensate), natural gas plant liquids, other liquids and refinery gains. Colin Campbell definition excludes heavy oil (>17.5 deg API), bitumen, oil shale, shale oil, deepwater oil and gas ( $>500 \mathrm{~m})$, polar oil and gas, and NGL from gas and plants.

Source: EIA and Colin Campbell Forecasts.

The model presented in this paper features an oil demand function driven by world GDP growth and the world business cycle. The oil supply curve incorporates the fact that oil can become increasingly harder to extract during certain episodes for a given oil extraction technology. The supply curve also takes into account the fact that breakthroughs in extraction technology can result in significant and persistent increases in supply. Oil prices act to equilibrate oil supply and demand. The model provides a useful analytical framework to construct macroeconomic scenarios showing the consequences of, including but not limited to: changes in world GDP growth; changes in the efficiency of oil usage; and changes in the supply of oil. Notwithstanding that shale oil production today is more responsive to prices than 
conventional oil, our analysis suggests that an era of prolonged low oil prices and investment is likely to be followed by a period where oil prices overshoot their long-term upward trend.

This paper contributes to the existing empirical literature on the link between oil prices and the macroeconomy. The results from early studies in the literature suggest that oil price fluctuations, implicitly assumed to result from changes in oil supply, had significant and negative effects on the economy (see Hamilton, 1996 and 2003). In particular, Hamilton (1983) shows that all but one U.S. recession since World War II were preceded by spikes in oil prices. More recent studies, however, point to a weakening relationship between oil prices and economic growth (e.g., Blanchard and Galí, 2007). These authors find much larger effects of oil price shocks on inflation and real economic activity in the 1970s than in the 2000s.

The weakening relationship between oil prices and the macroeconomy can partly be attributed to changes in the underlying shocks driving oil prices. Oil price increases induced by supply shocks, according to several authors using structural VAR models, have much more pronounced effects on the economy than those due to demand shocks (e.g., Peersman and Van Robays, 2012; Lippi and Nobili, 2012). In recent decades, oil supply shocks alone, generally represented by disruptions to global crude oil production, cannot explain the bulk of oil price fluctuations (e.g., Kilian, 2009). Instead, oil demand stemming from fast-growing emerging-market economies has been the primary driver of oil prices. Another explanation for the weakening relationship lies in changes in the transmission of shocks. Blanchard and Galí (2007) and Blanchard and Riggi (2013) provide evidence that the transmission of oil price shocks can change with the structure of the economy and policy framework. For example, continued energy efficiency gains achieved over the past decades in advanced economies mitigated some of the negative effects from higher oil prices. ${ }^{1}$

While these empirical models have been useful to gain insights into the source of shocks behind oil price fluctuations in the short run, they are not well-suited to explore the interdependencies of demand and supply, and the complex web of interactions beyond any short horizon. The model presented in this paper, instead, provides a useful framework to construct alternative scenarios with oil prices, oil production, and world GDP growth under different assumptions about shocks over the medium term.

The remainder of the paper is organized as follows. Section II presents the prevailing views embodied in existing models of the oil market. Section III presents the structure of the model and its properties. Section IV lays out illustrative scenarios based on different assumptions

\footnotetext{
${ }^{1}$ Other explanations include: more flexible labor markets and weaker unions that have led to lower real wage rigidities; monetary policy that has gained credibility and has therefore been more effective in ensuring that oil price shocks do not feed into core inflation (which in turn has kept central banks from needing to adjust policy interest rates in the aftermath of an oil shock).
} 
about longer-term world GDP growth, oil consumption efficiency improvements, and future oil supply conditions. Section V presents extensions of the model. Section VI concludes.

\section{The Prevailing "Views" in Existing Models of The OIL Market}

Existing views of the oil market typically have one or only some of the following key essential insights. One, depletion forces will dominate the future of oil supply, and oil prices will rise as these forces become more binding. Two, future oil demand will be satisfied without a large and sustained increase in the real price of oil thanks to improvements in oil exploration and extraction technology. Three, the world business cycle will drive future oil demand, and oil prices will start rising when the global economy starts to pick up. Four, oiluse efficiency has been improving and will continue to improve, and this will help offset the increase in the demand for oil from fast-growing emerging market economies.

\section{II.1. "Constrained Supply" View}

The "constrained supply" view typically starts with the idea that existing conventional oil fields, which account for about 80 percent of current supply, are depleting rapidly. The depletion rate for existing conventional oil fields is estimated to be between 3 and 4 percent per annum by the International Energy Agency (IEA), which means that significant new sources of oil supply will be needed to meet the growing demand. Table 1 shows that at current depletion rates, existing conventional oil fields will shrink from supplying 68.3 million barrels of oil per day in 2015 to 44.6 million barrels per day by 2025 , resulting in a shortfall of 23.7 million barrels per day that will need to be filled just to keep oil production constant.

Table 1. World Oil Production by Type in the New Policies Scenario (in millions of barrels per day)

\begin{tabular}{l|cccc} 
& $\mathbf{2 0 0 0}$ & $\mathbf{2 0 1 5}$ & $\mathbf{2 0 2 0}$ & $\mathbf{2 0 2 5}$ \\
\hline Conventional Production & $\mathbf{7 3 . 8}$ & 83.8 & 83.0 & 83.6 \\
Crude oil & 64.8 & 68.3 & 66.4 & 65.5 \\
$\quad$ Existing fields & 64.8 & 68.3 & 57.0 & 44.6 \\
$\quad$ Approved and not producing & & & 5.8 & 5.0 \\
$\quad$ Yet-to-be-approved & - & - & 3.5 & 15.9 \\
$\quad$ Yet-to-be-found & - & - & - & 2.9 \\
Natural gas liquids & 9.0 & 15.5 & 16.6 & 18.0 \\
\hline
\end{tabular}

Notes: (1) $68.3 \mathrm{mb} / \mathrm{d}-44.6 \mathrm{mb} / \mathrm{d}=23.7 \mathrm{mb} / \mathrm{d}$ that need to be replaced. This represents depletion rate of $100 *\left(1-(44.6 / 68.3)^{\wedge}(1 / 11)\right)=3.8$ percent per annum.

(2) Substantial investment is needed just to keep the production at current levels.

Source: International Energy Agency World Energy Outlook 2016, Table 3.11. 


\section{II.2. "Elastic Supply" View}

The "elastic supply" view of the oil market focuses on the idea that higher prices eventually stimulate oil supply by encouraging investment in exploration. Indeed, unconventional sources of oil supply have taken up the slack as conventional sources leveled off. Figure 3 shows the dramatic rise in unconventional oil supply as a result of rising oil prices and increased investment, some evidence suggesting that Campbell's forecasts of oil production have been overly pessimistic.

Figure 3. Unconventional Oil Investment and Production

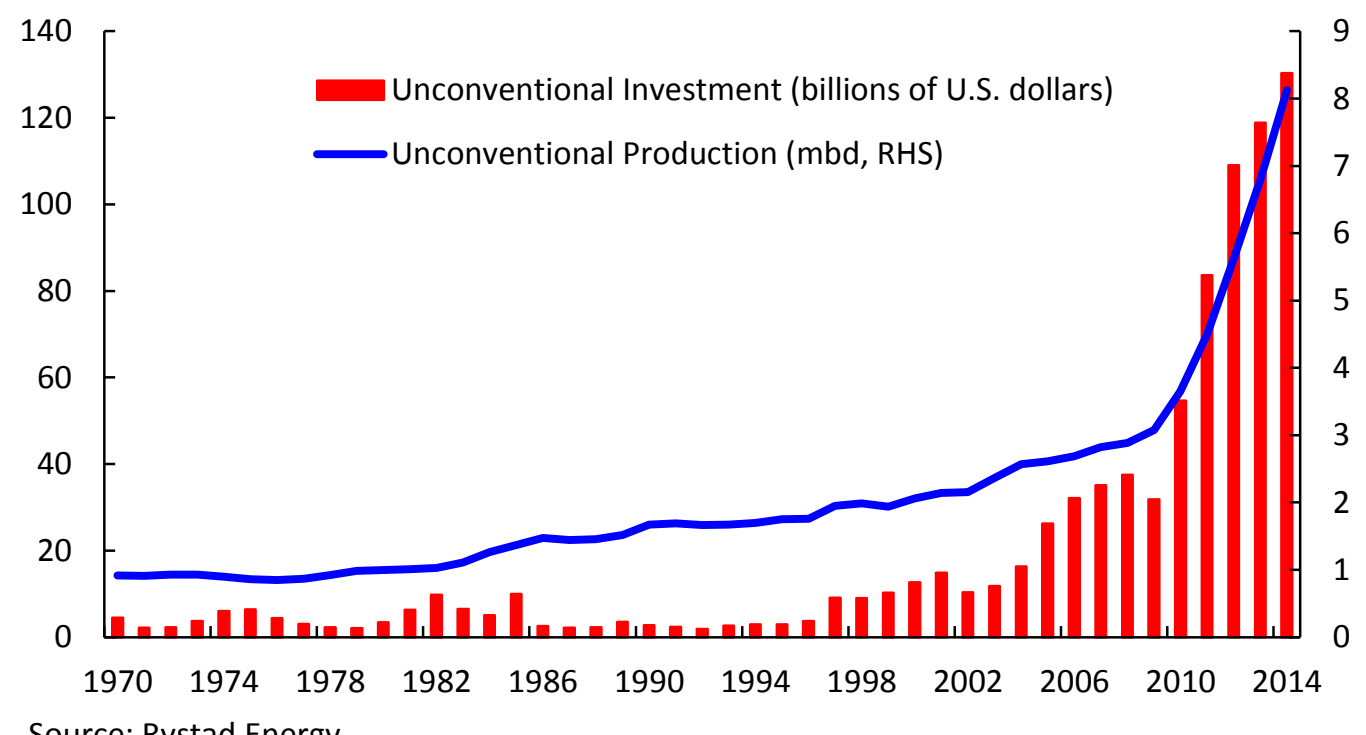

There are three types of unconventional oil supply: shale oil; ultra-deep water oil; and oil sands. Of these, shale oil has the greatest potential to provide a significant increase in supply over the next decade owing to rapidly declining costs of extraction and potential for discovering new fields. The other sources of unconventional oil require long investment lead times and enormous investment in extraction infrastructure to ramp up production. Table 2 provides illustrative estimates of production potential of those unconventional sources over the next decade.

The cost of extraction can be quite different for different types of unconventional oil. This implies that where oil prices go depends crucially on the price of the marginal barrel of oil. This gives rise to a "break-even" cost curve, which maps out the price of oil at which a new oil extraction project would become economical for different types of oil, assuming oil prices and costs remained constant going forward. Figure 4 provides an example of a "break-even" cost curve based on information as of December, 2015. Since then, improvements in extraction technology have resulted in downward shifts in certain segments of this cost curve (e.g., shale oil). 
Table 2. Projected World Oil Production

(in millions of barrels per day)

\begin{tabular}{lcc}
\hline World oil supply* & 2015 & 2025 (Change from 2015) \\
... of which & 94 & $100(+6)$ \\
$\quad$ Shale/tight Oil (mostly U.S.) & 7 & $10(+3)$ \\
$\quad$ Ultra-deep water (>1500 meters) & 2 & $3(+1)$ \\
$\quad$ Oil sands (mostly Canada) & 2 & $3(+1)$ \\
\hline
\end{tabular}

*Assumes flat conventional crude oil production. The increase in the supply of shale oil, ultra-deep water oil, and oil sands do not add up to the increase in total supply as there are other categories such as natural gas liquids.

Source: Rystad Energy, International Energy Agency, and authors' calculations.

Figure 4. Illustrative Oil Supply “Break-even” Cost Curve as of December, 2015

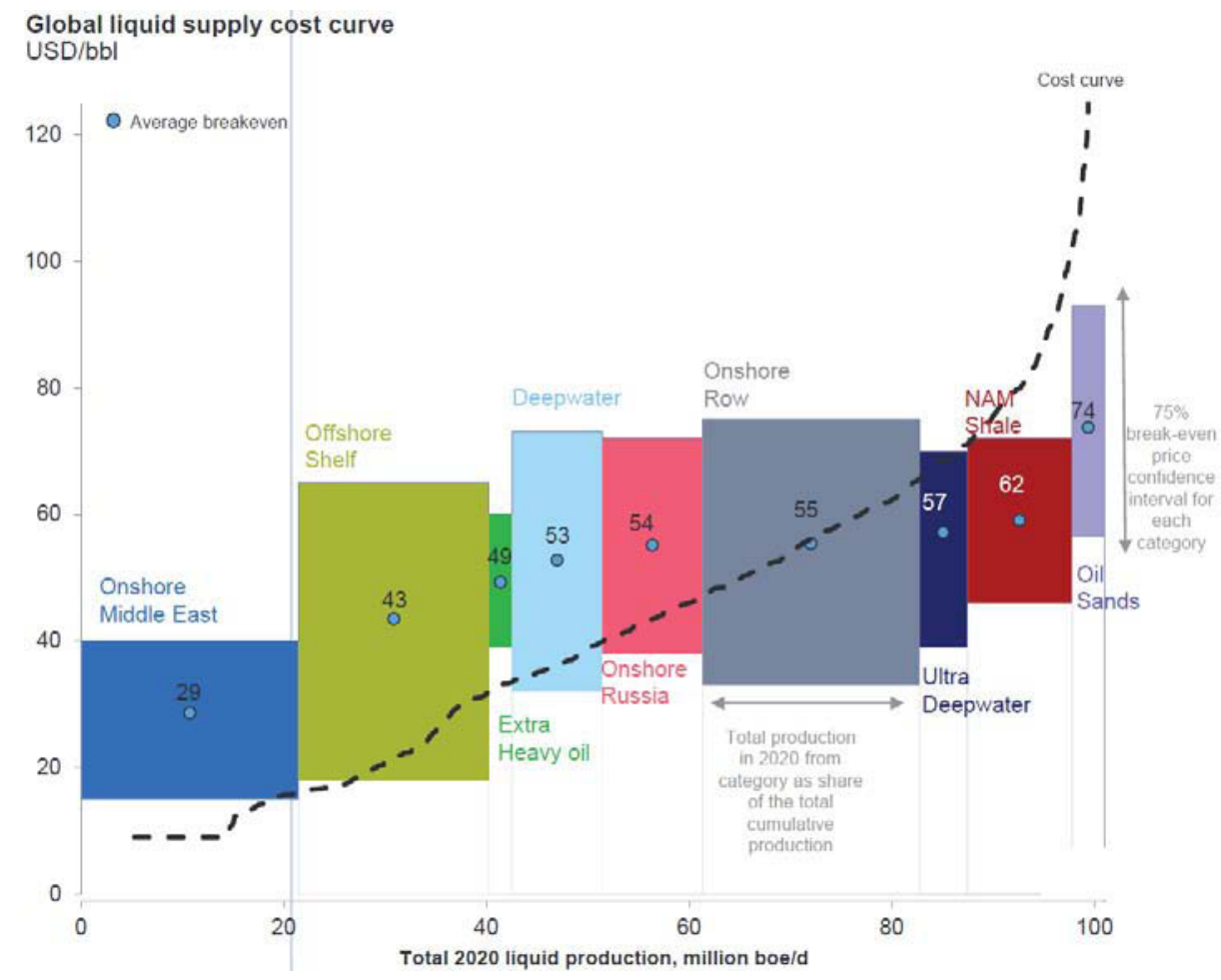

Source: Rystad Energy.

\section{II.3. "World Business Cycle" View}

According to the "world business cycle" view, oil price fluctuations are mainly driven by demand factors. Strong world trend output growth, especially in emerging markets, could result in an upward trend in oil prices. A reasonable estimate is that by 2025 an additional 6 
million barrels per day may be needed to support world GDP growth of around 3.8 percent per annum. Behind this estimate are fairly optimistic assumptions about shale oil supply (Table 2) and improvements in oil-use efficiency.

With a shorter horizon, the world business cycle could also drive oil prices because demand and supply are more inelastic in the short run. Cyclically strong world growth at a time when oil supply spare capacity is low can trigger an episode with persistently high oil prices. For example, 2003-08 was a period when the oil market was very tight, as indicated by very low levels of OPEC short-term spare capacity (Figure 5).

Figure 5. Oil Prices and OPEC Spare Capacity
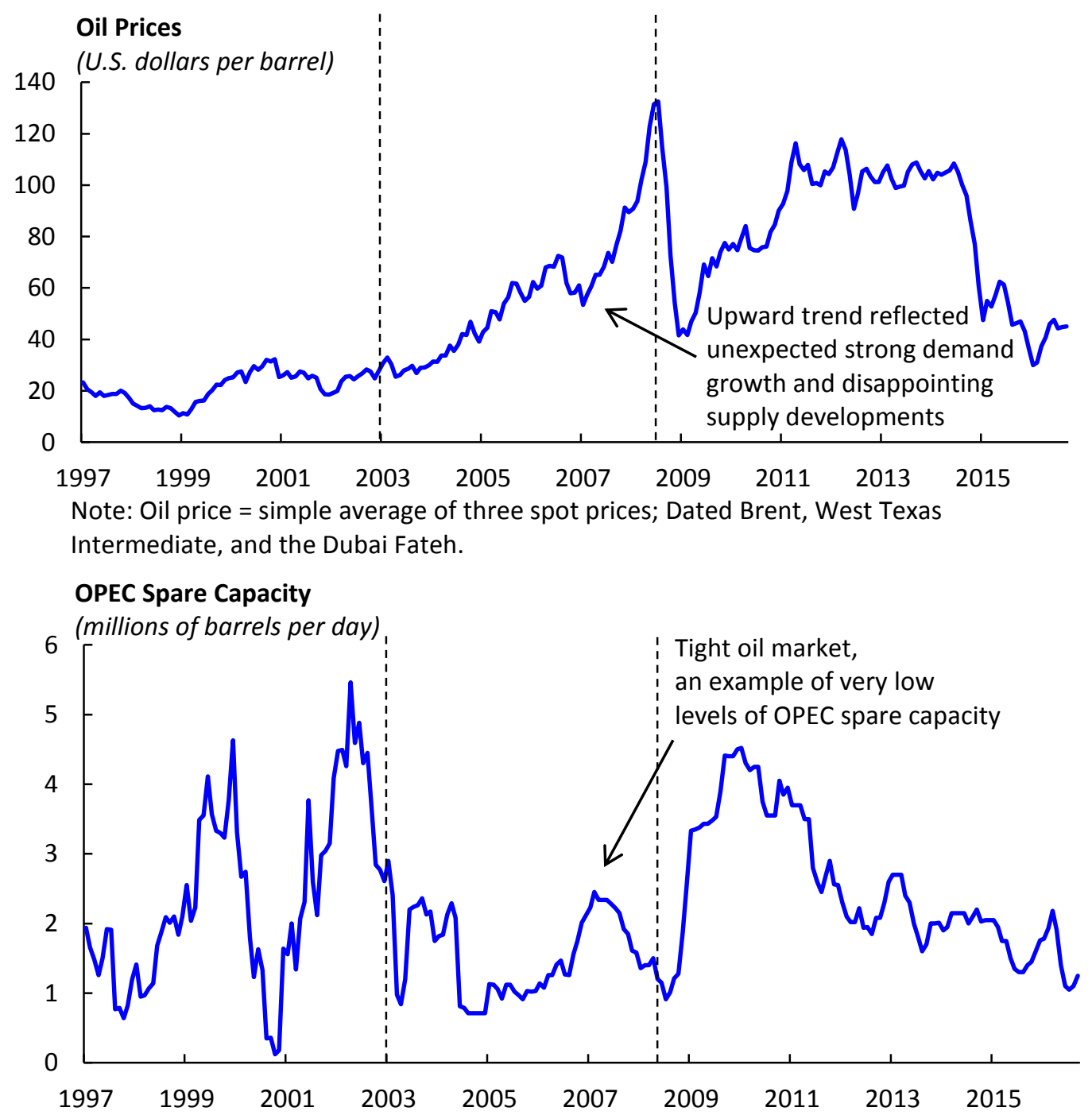

Source: Oil prices from IMF, Primary Commodity Price System. OPEC spare capacity from U.S. Energy Information Administration. Last Observation: September 2016. 


\section{II.4. "Substitution and Conservation" View}

According to this view, efforts towards oil substitution and conservation are the dominant forces in shaping the oil market. Currently oil is mainly used for transportation, while other fossil fuels such as coal and natural gas, are mostly used for power generation. However, oil still faces competition from other sources of energy. As the price of oil rises, the demand for oil decreases as consumers switch to substitutes such as biofuels or natural gas.

The biggest new competitor to oil in the transportation sector is arguably natural gas. It is the cleanest source of energy among fossil fuels, which could help limit carbon emissions and promote compliance to COP2 1 commitments. Natural gas is expected to make significant further inroads into transportation, for example, through the use of liquefied natural gas as shipping fuel. More importantly, more extensive use of electric cars could enable the "electrification" of the transportation sector, making natural gas central to the provision of energy to that sector. The share of oil in global primary energy consumption has declined from 50 percent in 1970 to about 30 percent today, whereas the share of natural gas has risen to nearly 25 percent. According to IEA projections, natural gas consumption will increase significantly in the medium term, at the expense of oil, with emerging markets and developing economies accounting for the bulk of the growth.

Oil conservation efforts can also lead to a reduction in oil demand going forward. As the price of oil rises, price incentives for developing and implementing oil-efficient technologies are higher. In addition, improved fuel-efficiency standards, as well as aging populations, are resulting in a downward trend in oil usage in most advanced economies, especially in the United States (Council of Economic Analysis, 2015a, 2015b). Figure 6 shows the historical trend decline in the world oil-consumption-to-GDP ratio and a projection based on assumptions about future improvements in the fleet efficiency of the car and truck stock.

Improvements in the fuel efficiency of automobiles have been a significant contributor to this downward trend. Figure 7 shows the rising miles per gallon (MPG) for new cars sold in the United States. In emerging markets where the middle class is growing rapidly, it is unclear whether improvements in fuel efficiency can offset the increasing demand for transportation services. Based on past empirical relationships, car ownership in emerging markets would be projected to reach fairly high levels over the next decade as income levels catch up to those in advanced economies (Figure 8). 
Figure 6. World Oil-Consumption-to-GDP Ratio

(barrels/real GDP, normalized to 1 in 1971)

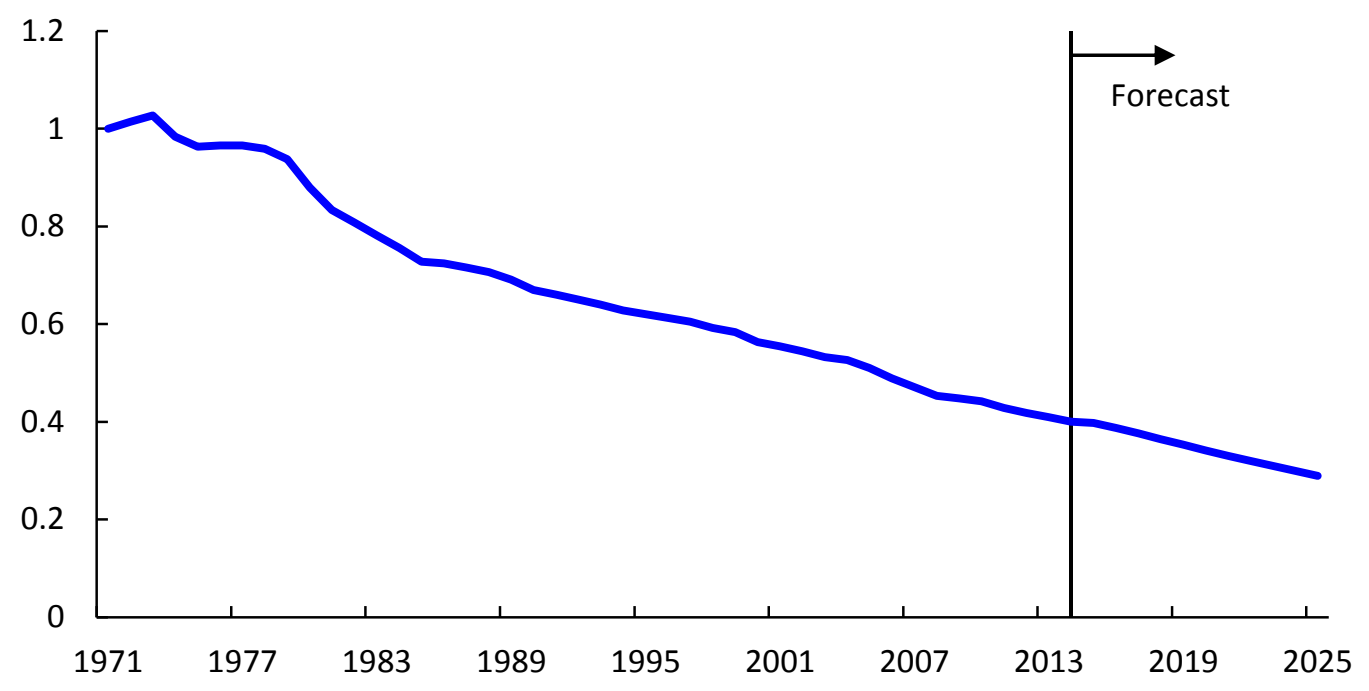

Source: International Energy Agency, authors' calculations.

Figure 7. Fuel Economy of New Cars in the U.S.

(in miles per gallon)

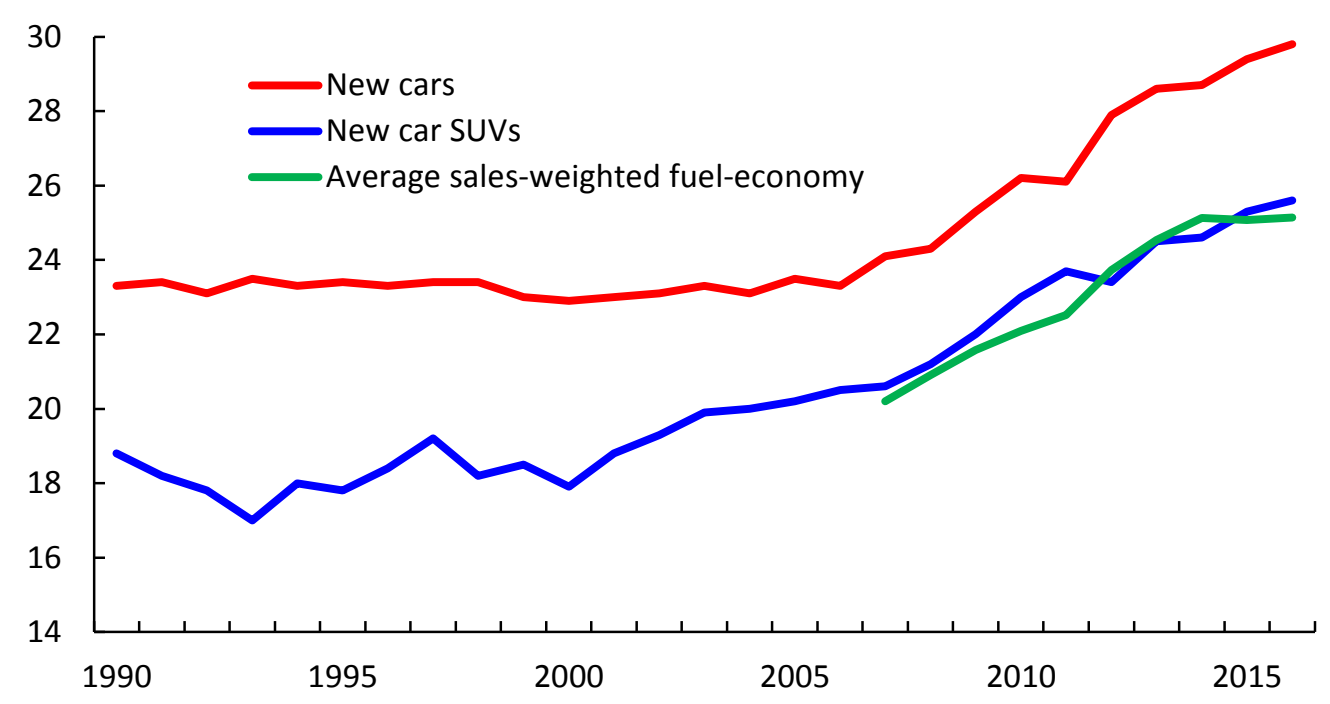

Source: United States Environmental Protection Agency; Transportation Research Institute, University of Michigan. 
Figure 8. Car Ownership in 2013 versus 2000

\section{Car Ownership - 2013}

(size of bubble represents population in 2013)

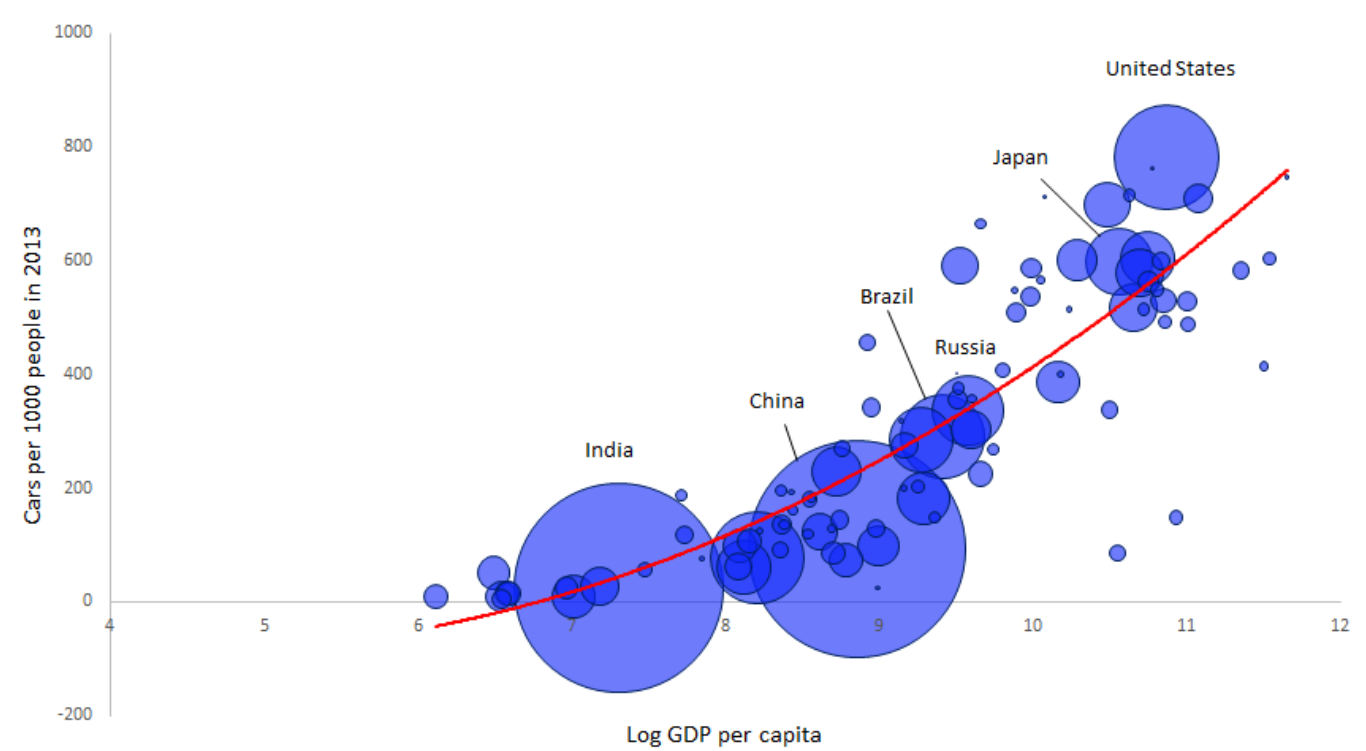

Sources: World Economic Outlook Database, International Monetary Fund; World Road Statistics, International Road Federation; and IMF staff calculations.

Note: Cars per 1000 people for India is from 2012, as is most recent available.

\section{Car Ownership 2000}

(size of bubble represents population in 2000)

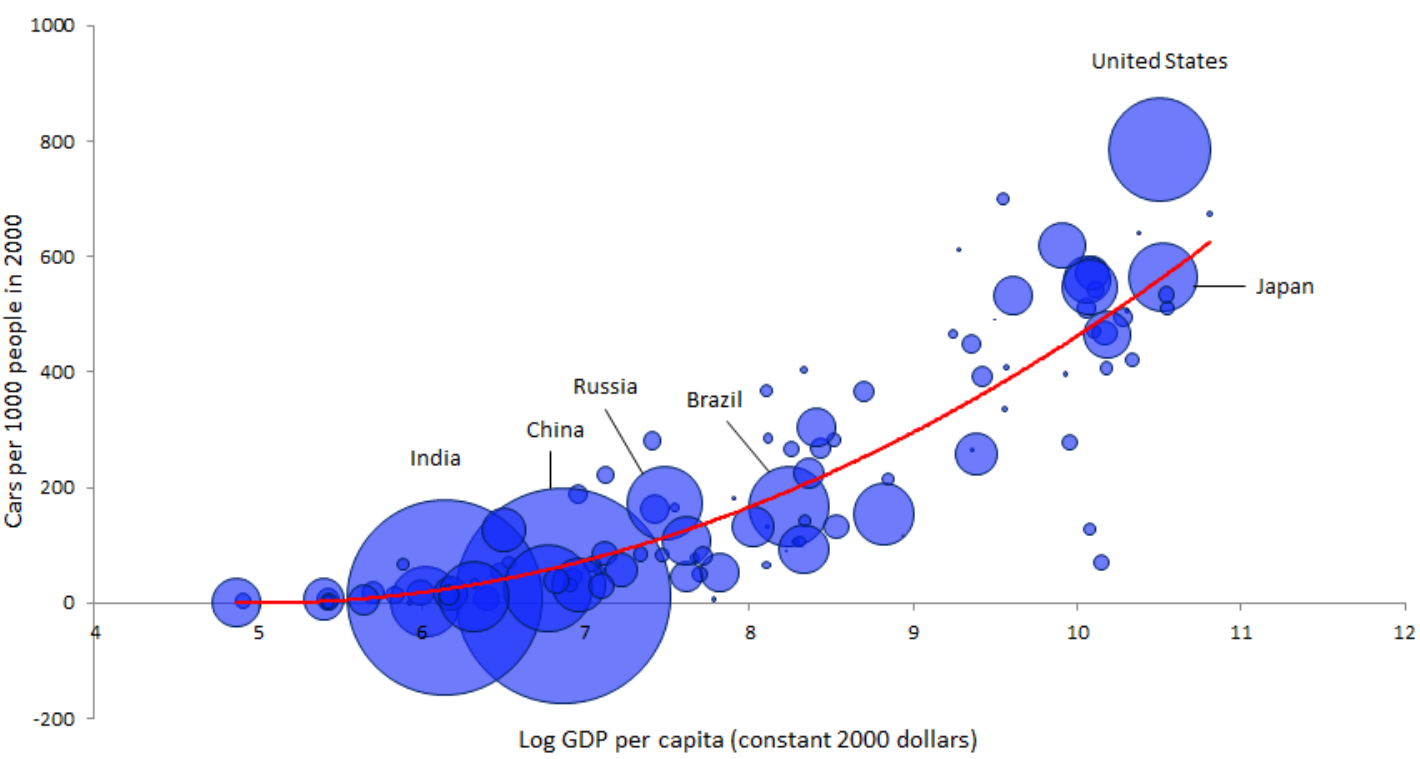

Sources: World Economic Outlook Database, International Monetary Fund; World Road Statistics, International Road Federation; and IMF staff calculations. 


\section{An INTEGRATEd MOdel OF SUPPLy AND DEMAND}

\section{III.1 Structure of the Model}

The model integrates the four views of the drivers of the oil market into a model based on the fundamentals of demand and supply. First, oil supply can be constrained in the short run by oil-extraction technology. Second, oil supply is more elastic in the medium to long run, in the sense that supply can eventually rise in response to higher oil prices due to innovations in oil exploration and extraction technologies. Third, demand factors, mainly world trend output growth and business cycles, can drive the demand for oil and thereby oil prices. Fourth, oil substitution and conservation, such as the use of alternative and renewable energy sources, and improvements in oil-use efficiency, can also be important for understanding the oil market. Finally, the model assumes that oil prices adjust instantaneously and continuously to clear the oil market.

The main model equations are presented below.

\section{Oil Supply}

$$
\frac{q_{t}}{Q_{t}}=\alpha_{s}-\beta_{1 t} Q_{t}+\beta_{2}\left(p_{t}\right)^{\theta}+\beta_{3} \frac{1}{3} \sum_{k=4}^{6}\left(p_{t-k}\right)^{\theta}+\varepsilon_{t}^{s}
$$

The definitions of the variables are: $q_{t}$ for annual oil production; $Q_{t}$ for cumulative production; $p_{t}$ for the real price of oil; and $\varepsilon_{t}^{s}$ for temporary oil supply disturbances. The supply of oil is influenced by two fundamental factors. First, as cumulative oil production increases, it becomes harder and harder to extract an additional barrel of oil given existing geological and technological constraints. ${ }^{2}$ The extent to which such constraints become binding depends on the magnitude of $\beta_{1 t} . \beta_{1 t}$ is time-varying because a breakthrough in extraction technology, or a discovery of new oil fields, will cause $\beta_{1 t}$ to drift down, resulting in a more persistent increase in oil supply compared to a positive but transient supply shock driven by $\varepsilon_{t}^{s}$. Second, the parameters $\beta_{2}$ and $\beta_{3}$ try to capture the traditional supply-curve effect where a rise in oil prices increases the quantity supplied. $\beta_{2}$ is the principal determinant of the short-run elasticity of supply, reflecting the ability of oil producers to expand supply based on existing capacity. The long-run elasticity of supply is determined mainly by the sum of $\beta_{2}$ and $\beta_{3}$. For example, a permanent increase in the price of oil would make the use of higher-cost extraction technologies profitable and encourage greater exploration effort. Such effect occurs with a lag though, mainly because it takes time to implement new extraction technologies and put newly-discovered oil fields into production.

\footnotetext{
${ }^{2}$ The logistic function for oil extraction is often used in modeling extraction probabilities in the geological literature.
} 
The parameter $\theta$ is another important determinant of the short-run and long-run supply elasticities in the model, determining the sensitivity of quantities to prices.

Figure 9 shows the time-varying supply elasticities in the model. For example, breakthrough in extraction technology, as was the case of shale oil, would cause $\beta_{1 t}$ to drift down and supply elasticities to increase. This would be consistent with the latest developments in the oil market before the global financial crisis - high prices encouraged investment in high-cost oil extraction, which eventually led to large increases in oil production. Similarly, according to the majority of experts, short-run elasticity of supply increased after the exploitation of shale oil, which is consistent with the predictions of the model.

Figure 9. Supply Elasticity

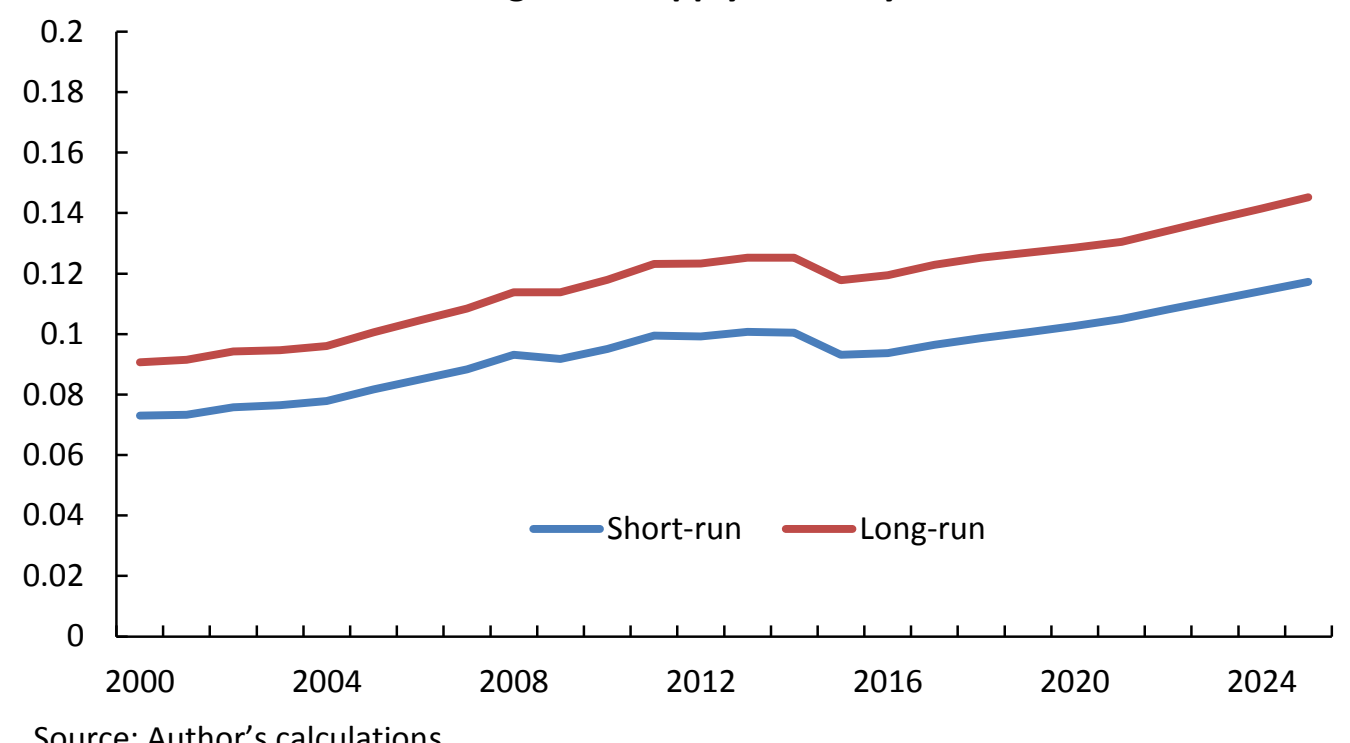

\section{Oil Demand}

$$
\log \left(\frac{q_{t}}{q_{t-1}}\right)=\alpha_{d}+\gamma_{1}\left(Y_{t}-Y_{t-1}\right)-\gamma_{2} \log \left(\frac{p_{t}}{p_{t-1}}\right)-\gamma_{3} \log \left(\frac{1}{9} \frac{p_{t-1}}{p_{t-10}}\right)+\varepsilon_{t}^{d}
$$

The oil demand equation captures three determinants of demand. First, the demand for oil grows with world GDP growth. The parameter $\gamma_{1}$ represents the elasticity of oil demand growth with respect to world GDP growth. The parameter $\gamma_{2}$ represents the short-run price elasticity of demand, while the sum of $\gamma_{2}$ and $\gamma_{3}$ is the long-run elasticity of demand. The latter includes a ten-year lag, reflecting the time it takes to improve the fleet efficiency of the stock of automobiles in response to a sustained increase of oil prices.

\section{World GDP}

World GDP is equal to trend world GDP plus the world output gap. 


$$
\mathrm{Y}_{t}=\overline{\mathrm{Y}}_{t}+y_{t}
$$

The definitions of the variables are: $Y_{t}$ and $\bar{Y}_{t}$ for the logarithms of actual and trend output, respectively, and $y_{t}$ for the world output gap.

Trend output is affected by the trend growth rate $g_{t}$ as well as a stochastic shock $\varepsilon_{t}^{\bar{Y}}$ that captures level shocks to trend output.

$$
\overline{\mathrm{Y}}_{t}-\overline{\mathrm{Y}}_{t-1}=g_{t}+\varepsilon_{t}^{\bar{Y}}
$$

The trend growth rate $g_{t}$ varies over time, capturing varying rates of capital accumulation, world labor force growth, and total factor productivity growth. It is negatively affected by rising oil prices. $g$ represents the long-run autonomous source of growth. $\rho$ represents the trend growth rate of the real oil price, which is approximately 7 percent over the historical sample used in the estimation (1983-2014). It reflects the threshold of the real oil price growth rate after which the negative effects on world trend growth start to kick in.

$$
g_{t}=\lambda_{1} g_{t-1}+\left(1-\lambda_{1}\right) g-\lambda_{2}\left(\log \frac{p_{t}}{p_{t-1}}-\rho\right)-\lambda_{3}\left(\log \frac{p_{t-1}}{p_{t-2}}-\rho\right)+\varepsilon_{t}^{g}
$$

The world output gap measures the position of the world business cycle.

$$
y_{t}=\varphi_{1} y_{t-1}+\varphi_{2}\left(y_{t-1}-y_{t-2}\right)-\varphi_{3}\left(\log \frac{p_{t}}{p_{t-1}}-\rho\right)-\varphi_{4}\left(\log \frac{p_{t-1}}{p_{t-2}}-\rho\right)+\varepsilon_{t}^{y}
$$

According to this equation, oil prices are potentially important factors affecting world economic upturns and downturns. Lower oil prices increase world cyclical output, in part because of the higher marginal propensity to consume out of income in oil-importing countries than in oil-exporting countries. Similar to the equation for world potential growth $g_{t}$, the parameter $\rho$ reflects the rate of growth of the trend real oil price after which the negative effects from higher oil prices start to kick in.

\section{III.2 Estimation}

The model is estimated with annual data using nonlinear Bayesian estimation techniques. Annual oil production data comes from the IEA's Monthly Oil Market Report database. It includes crude oil, natural gas liquids, and refinery processing gains (biofuels are excluded). The measure of real oil prices is derived from the IEA's oil import price deflated by the U.S. CPI, with a base year of 2013. Data for world real GDP correspondents to the IMF's World Economic Outlook real GDP data. The sample period is 1983 through 2014. 
Fairly tight priors are imposed on the parameters determining oil demand, the GDP trend, and the GDP gap equations. These priors are based on existing empirical work. For the oil supply equation, where there is almost no guidance from previous studies, very loose priors are used. As the supply curve is nonlinear, the extended Kalman filter is used. The model is estimated as a system. The posterior distributions of parameters are obtained using an adaptive random-walk algorithm. Table 3 provides a summary of the estimation results.

As very few empirical studies exist on both short-term and long-term supply elasticities, flat priors are used for the oil production equation letting the data determine the parameter values. Importantly, the values of $\beta_{2}$ and $\beta_{3}$ should not be confused with supply elasticities as the supply curve is nonlinear, and, hence, the elasticities are time-varying, depending not only on the parameters $\beta_{2}$ and $\beta_{3}$ but also on the cumulative production and $\beta_{1}$. This is a desirable feature of the model as supply elasticities may vary widely from times when

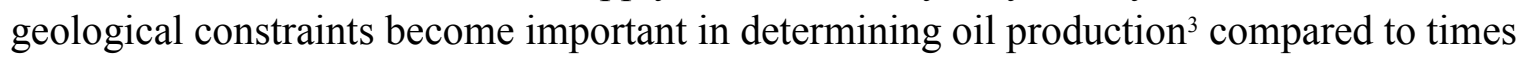
when occasional supply bursts are experienced after the adoption of new technologies ${ }^{4}$.

The short data span and the complexity of the oil market make the estimation quite difficult. However, the model provides a useful framework that can be used to think in a more structured way about parameter and shock uncertainty, especially when the future could potentially be quite different from history. Scenarios presented in Section IV are illustrations of the value of the framework as it allows us to generate consistent scenarios with different assumptions about underlying fundamentals of the oil market and the world economy.

\section{III.3 Model Properties}

In this section, we examine the model properties by looking at the impulse response functions to various shocks (see Figure 10).

\section{Oil Demand Shock}

A one-year, one-standard-deviation positive shock to the growth rate of oil demand leads to a permanent increase in the level of oil demand. Given that it takes time for supply to fully catch up to demand, oil prices immediately rise by over 8 percent. Higher prices encourage additional exploration efforts and exploit new extraction technologies, which leads to a sustained increase in oil production. Over time, higher oil prices also encourage oil substitution and conservation measures. World GDP is down by about 0.3 percent after a decade as a result of the shock.

\footnotetext{
${ }^{3}$ Most analysts argue that the run up of oil prices before the global financial crisis was due to the difficulty of extracting conventional oil to meet the fast-growing demand from emerging economies, particularly China.

${ }^{4}$ The impressive increase of shale oil supply in the U.S. is a good example.
} 
Table 3. Parameter Estimates

\begin{tabular}{|c|c|c|c|c|c|c|c|c|c|c|c|}
\hline & \multirow[b]{2}{*}{ Parameter } & \multicolumn{2}{|c|}{ Bounds } & \multicolumn{4}{|c|}{ Prior Distrubution } & \multicolumn{4}{|c|}{ Posterior Distrubution } \\
\hline & & Lower & Upper & Distribution Type & Mode & Mean & $\begin{array}{l}\text { Standard } \\
\text { Deviation }\end{array}$ & Mode & Mean & $\begin{array}{l}\text { Highest P } \\
\text { Density Inte }\end{array}$ & $\begin{array}{l}\text { erior } \\
\text { of } 90 \% \\
\end{array}$ \\
\hline \multirow{4}{*}{$\begin{array}{l}\stackrel{0}{3} \\
\frac{3}{0} \\
\frac{1}{2} \\
\frac{0}{0} \\
\bar{n}\end{array}$} & $\alpha_{\mathrm{s}}$ & 0.0000 & 1000.0000 & uniform & - & - & - & 297.3137 & 311.1275 & 299.8365 & 318.0759 \\
\hline & $\beta_{2}$ & 0.0000 & 100.0000 & uniform & - & - & - & 15.0405 & 15.0082 & 14.8262 & 15.3004 \\
\hline & $\beta_{3}$ & 0.0000 & 100.0000 & uniform & - & - & - & 3.7722 & 3.0422 & 2.5794 & 3.6460 \\
\hline & $\theta$ & 0.0000 & 100.0000 & uniform & - & - & - & 0.1163 & 0.1197 & 0.1155 & 0.1244 \\
\hline \multirow{4}{*}{ 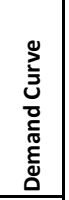 } & $\alpha_{d}$ & -0.1000 & 0.1000 & uniform & - & - & - & -0.0162 & -0.0194 & -0.0262 & -0.0136 \\
\hline & $\gamma_{1}$ & 0.5000 & 2.0000 & lognormal & 0.8867 & 0.9 & 0.09 & 0.8995 & 0.9758 & 0.8202 & 1.1156 \\
\hline & $V_{2}$ & 0.0050 & 0.2000 & inverse gamma & 0.0196 & 0.02 & 0.002 & 0.0209 & 0.0212 & 0.0185 & 0.0238 \\
\hline & $\gamma_{3}$ & 0.0200 & 0.1000 & inverse gamma & 0.0588 & 0.06 & 0.006 & 0.0569 & 0.0571 & 0.0470 & 0.0648 \\
\hline \multirow{5}{*}{ 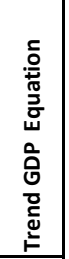 } & $\lambda_{1}$ & 0.5000 & 0.9900 & beta & 0.9007 & 0.9 & 0.009 & 0.9000 & 0.8998 & 0.8884 & 0.9151 \\
\hline & $\lambda_{2}$ & 0.0000 & 0.0300 & normal & 0.005 & 0.005 & 0.0015 & 0.0038 & 0.0042 & 0.0018 & 0.0058 \\
\hline & $\lambda_{3}$ & 0.0000 & 0.0300 & normal & 0.005 & 0.005 & 0.0015 & 0.0041 & 0.0043 & 0.0028 & 0.0064 \\
\hline & $\mathrm{g}$ & 0.0000 & 0.0500 & normal & 0.04 & 0.04 & 0.04 & 0.0323 & 0.0332 & 0.0307 & 0.0377 \\
\hline & $\rho$ & 0.0000 & 0.1000 & normal & 0.07 & 0.07 & 0.007 & 0.0689 & 0.0684 & 0.0584 & 0.0758 \\
\hline \multirow{4}{*}{ 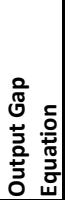 } & $\varphi_{1}$ & 0.3000 & 0.9900 & normal & 0.85 & 0.85 & 0.085 & 0.8145 & 0.8388 & 0.7396 & 0.9833 \\
\hline & $\varphi_{2}$ & 0.0500 & 0.9900 & normal & 0.25 & 0.25 & 0.025 & 0.2498 & 0.2530 & 0.2197 & 0.2914 \\
\hline & $\varphi_{3}$ & 0.0000 & 0.1000 & normal & 0.005 & 0.005 & 0.0015 & 0.0047 & 0.0046 & 0.0023 & 0.0070 \\
\hline & $\varphi_{4}$ & 0.0000 & 0.1000 & normal & 0.005 & 0.005 & 0.0015 & 0.0052 & 0.0054 & 0.0030 & 0.0073 \\
\hline \multirow{5}{*}{ 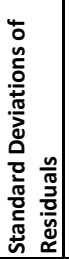 } & $\sigma\left(\varepsilon^{s}\right)$ & 0.0010 & 0.1000 & normal & 0.01 & 0.01 & 0.005 & 0.0262 & 0.0278 & 0.0221 & 0.0320 \\
\hline & $\sigma\left(\varepsilon^{d}\right)$ & 0.0010 & 0.1000 & normal & 0.01 & 0.01 & 0.005 & 0.0224 & 0.0239 & 0.0174 & 0.0287 \\
\hline & $\sigma\left(\varepsilon^{\nabla}\right)$ & 0.0001 & 0.1000 & normal & 0.001 & 0.001 & 0.0005 & 0.0010 & 0.0009 & 0.0002 & 0.0013 \\
\hline & $\sigma\left(\varepsilon^{\mathrm{g}}\right)$ & 0.0001 & 0.1000 & normal & 0.001 & 0.001 & 0.0005 & 0.0010 & 0.0013 & 0.0005 & 0.0019 \\
\hline & $\sigma\left(\varepsilon^{y}\right)$ & 0.0010 & 0.1000 & normal & 0.01 & 0.01 & 0.005 & 0.0172 & 0.0181 & 0.0138 & 0.0227 \\
\hline
\end{tabular}

Source: Authors' estimates.

\section{Transitory Shock to the World Output Gap}

A one-year, one-standard-deviation positive shock to the world output gap results in world output rising by around 0.9 percent after one year. Higher world output requires more oil as a factor of production, and as a result, oil prices and oil production are both higher. As the output gap gradually closes, oil prices and oil production both decline. The dynamics of the real price of oil mirror that of the world business cycle.

\section{Shock to World Trend GDP Growth}

A one-year one-standard-deviation shock to world trend GDP growth rate causes a permanent upward shift in the level of world trend output and opens up a negative output gap. As it takes time for actual output to catch up with trend output (and for output gap to 
close), world GDP rises gradually until it settles permanently at a higher level. The faster growth of the world economy leads to increased demand for oil, resulting in a 0.15 percent increase in oil production after 10 years. The increase in the real price of oil is permanent, converging to a 1 percent increase after 5 years.

\section{Transitory Shock to the Level of World Trend Output}

A one-year one-standard-deviation shock to the level of world trend output results in a small increase in world GDP, again because actual output converges gradually to the higher level of trend GDP. The limited reaction of actual output means that the resulting increases in oil production and the oil price are both small.

\section{Permanent Disruption in Oil Supply}

A permanent one-standard-deviation negative shock to oil supply results in a decline in oil production and an overshoot in oil price of where it eventually settles. The overshoot occurs because oil demand takes time to fall in response to higher oil prices. Permanently lower oil production leads to higher oil prices and permanently lower world output.

\section{Transitory Disruption in Oil Supply}

A one-year one-standard-deviation shock to oil supply produces an immediate reduction in oil production of about 0.3 percent. The oil price jumps by more than 10 percent as a result of such a supply disruption and world output drops by about 0.1 percent for two years. As the shock to oil supply is temporary, the oil price declines back to baseline in the second year. 
Figure 10. Impulse Response Functions

(percent deviation from baseline)
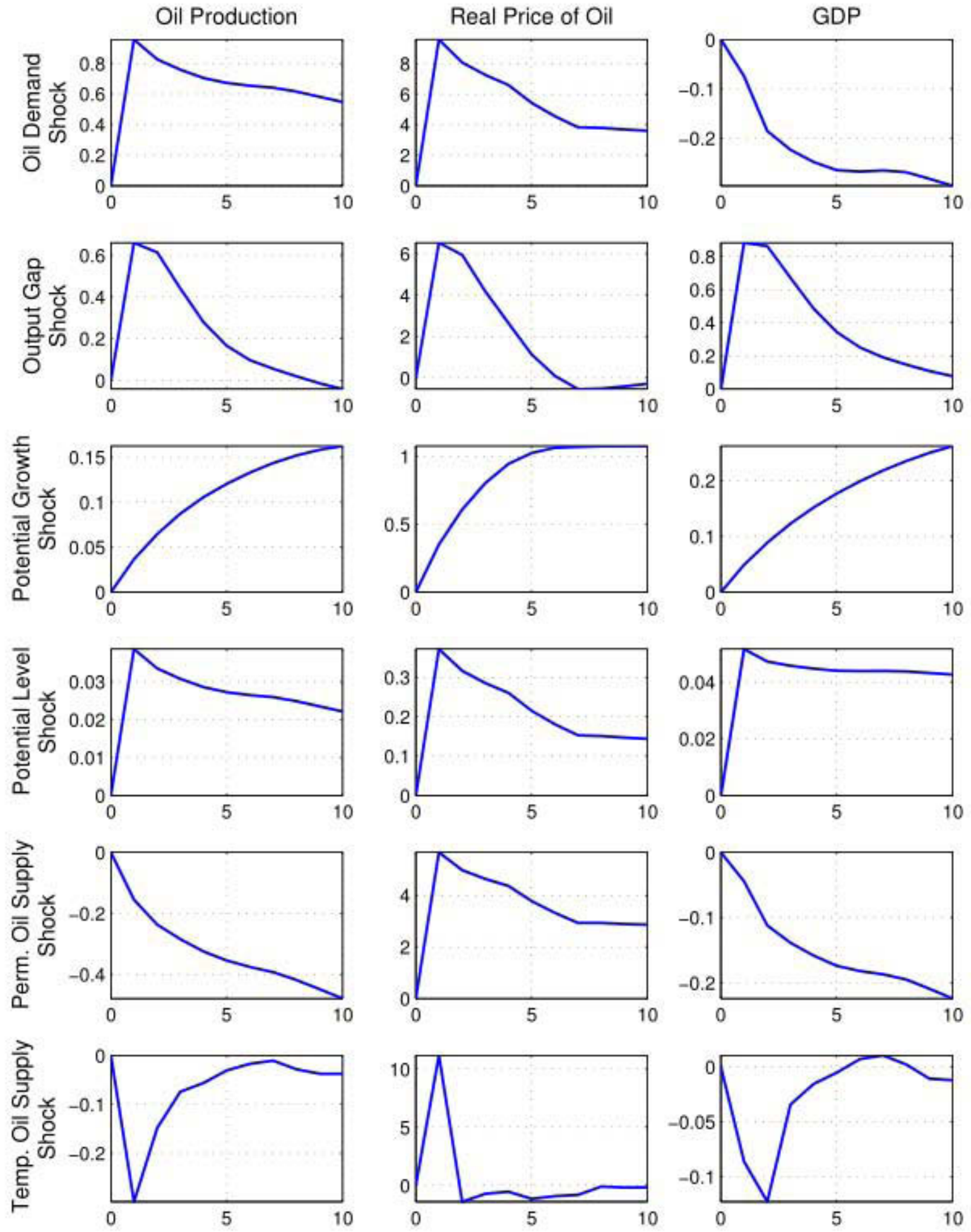

Source: Authors' calculations. 


\section{Illustrative Model Simulations}

The "constrained supply" and "elastic supply" views both turned out to be wrong because they both made extreme assumptions about the nature of price-quantity adjustment in the oil market. According to the "constrained supply" view, oil supply does not respond to price incentives, as exogenous geological constraints are the key determinants of supply. According to the "elastic supply" view, oil supply increases in response to rising demand without significant adjustment of prices. In the short run, these assumptions may be realistic. But over time, supply and demand become increasingly responsive to oil market conditions. The key advantage of our modeling framework is that it allows us to generate a range of alternative medium-term scenarios by making explicit assumptions about the medium-term responsiveness of oil supply and demand to oil market conditions. This is especially important in the current environment, given that there is considerable uncertainty about the extent to which shale oil producers can help with a smooth rebalancing of the oil market.

\section{IV.1 Smooth Rebalancing of the Oil Market}

In this subsection we present an illustrative scenario where the oil market achieves a smooth rebalancing over the medium term in spite of the abrupt decline in investment in the oil sector that resulted from the collapse in oil prices and subsequent low oil price environment. Even though we are not modelling separately shale oil production, the scenario illustrates a situation where shale oil production will help alleviate the shortfall in production in the medium term that will arise from lower additional conventional investments to meet the increasing demand for oil.

Figure 11 presents the projection of oil prices along with confidence bands. In the scenario, the long-run world GDP growth is assumed to be $3.8 \%$. In the short run, oil supply tends to be inelastic as geological factors determine the level of pressure from any given field and hence the level of production. In addition, this scenario assumes that shale production is resilient to lower prices. Specifically, shale oil production is assumed to remain unresponsive to lower oil prices for a considerable amount of time, hence the persistence of low oil prices. The period of stability is followed by a gradual rise of oil prices. Over time, the increase in oil prices is necessary to encourage greater exploration and exploitation of unconventional oil fields, and provides a renewed incentive for greater substitution and conservation. These forces limit the rise in oil prices and produces the plateau in oil prices over the longer term.

The wide confidence bands around the projected future oil prices reflect the considerable amount of uncertainty, a combination of both shock and parameter uncertainty. The greatest uncertainty lies in the timing of the longer-run responses of demand and supply to change in oil prices. 
Figure 11. Scenario of Smooth Rebalancing of the Oil Market

(in 2013 U.S. dollars per barrel)

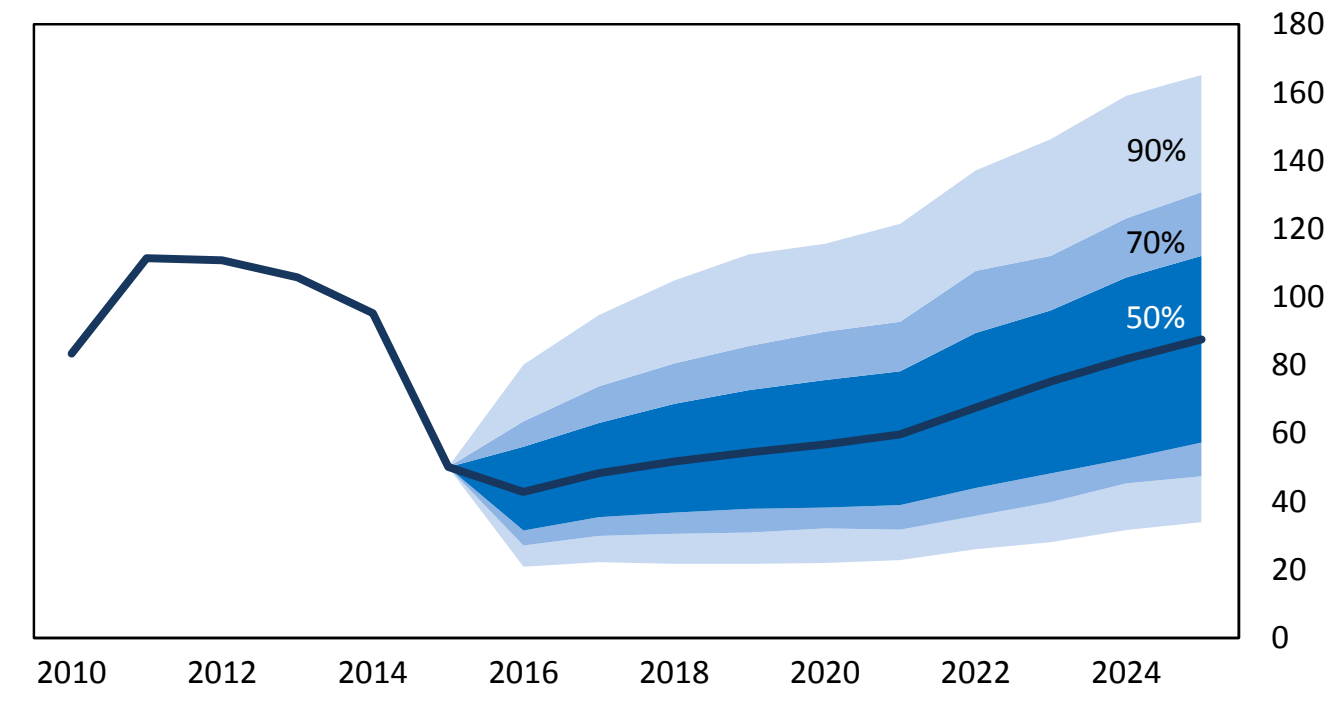

Source: Authors' calculations.

\section{IV.2 Alternative Scenarios}

\section{World GDP Growth Scenarios}

The scenarios presented in Figure 12 consider alternative assumptions about long-run world GDP growth. The optimistic and pessimistic growth scenario assume a 4 percent and 3.5 percent of long-run world GDP growth, respectively. The previous scenario, labeled "smooth rebalancing", is also shown in the figure for comparison purposes.

The optimistic world GDP growth scenario generates a path for future oil prices that rises to about 100 dollars a barrel within 10 years. This compares to the approximately 90-dollar oil price that is generated in the "smooth rebalancing" scenario. In the pessimistic growth scenario, where world GDP growth is assumed to decline gradually to 3.5 percent, oil prices rise to about 80 dollars a barrel within the next decade. In these scenarios, the differences in oil production are almost entirely related to the differences in oil prices.

\section{Consumption Efficiency Scenarios}

The scenarios in Figure 13 illustrate the impact of lower or higher oil-consumption efficiency on oil prices. Energy efficiency is defined in terms of the amount that the oil-consumptionto-world-GDP ratio declines each year, owing to new energy-reducing technologies and energy conservations efforts. In the lower and higher energy efficiency scenarios, the decline in the ratio of oil consumption to world GDP in the next ten years is 1 percentage point lower and higher, respectively, compared to the "smooth rebalancing" scenario. 
Figure 12. World GDP Growth Scenarios

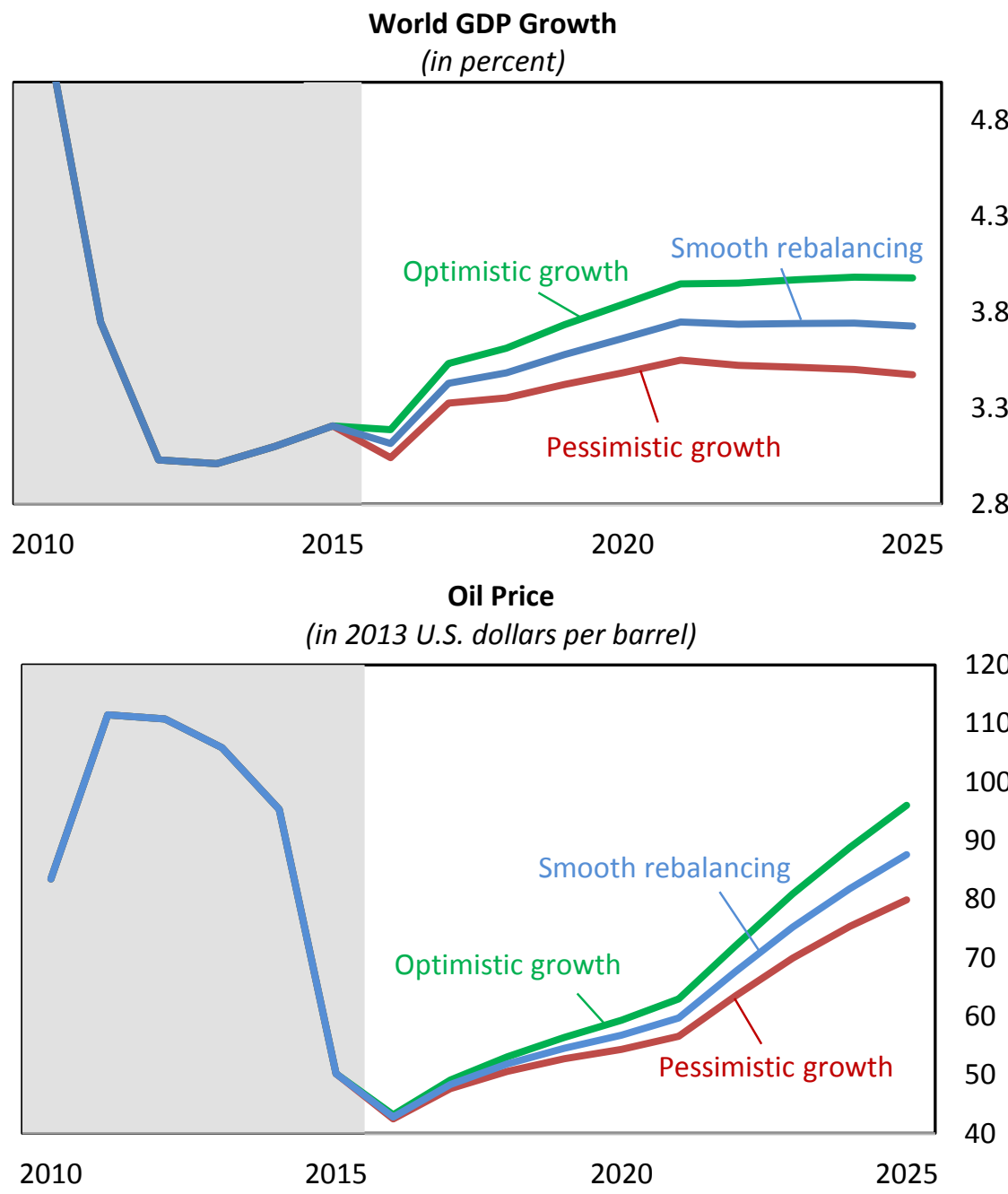

Oil Production

(in millions of barrels per day)

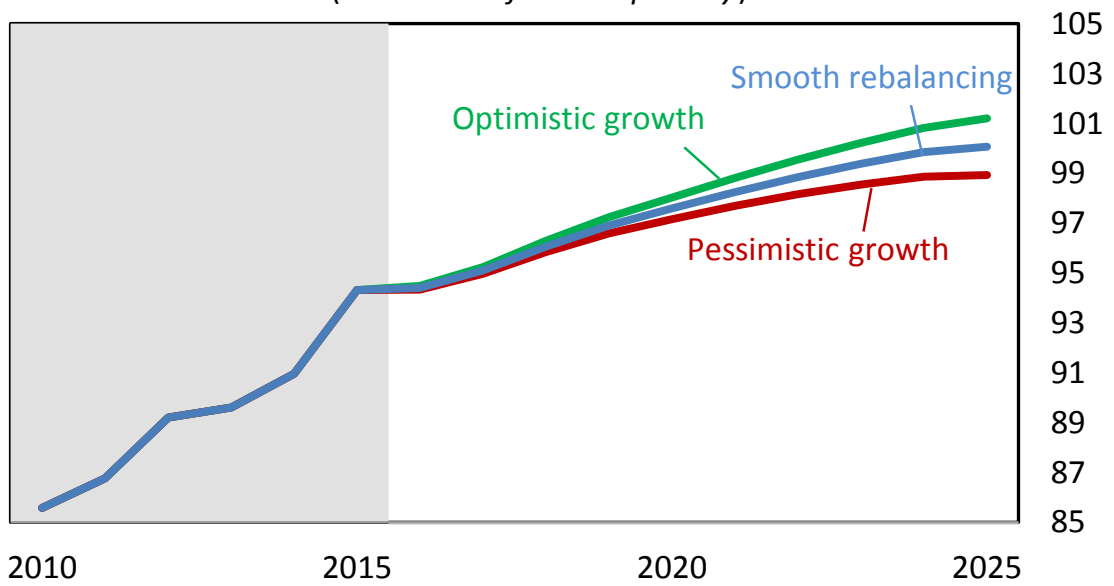

Source: Authors' calculations. 
Figure 13. Consumption Efficiency Scenarios

World GDP Growth

(in percent)

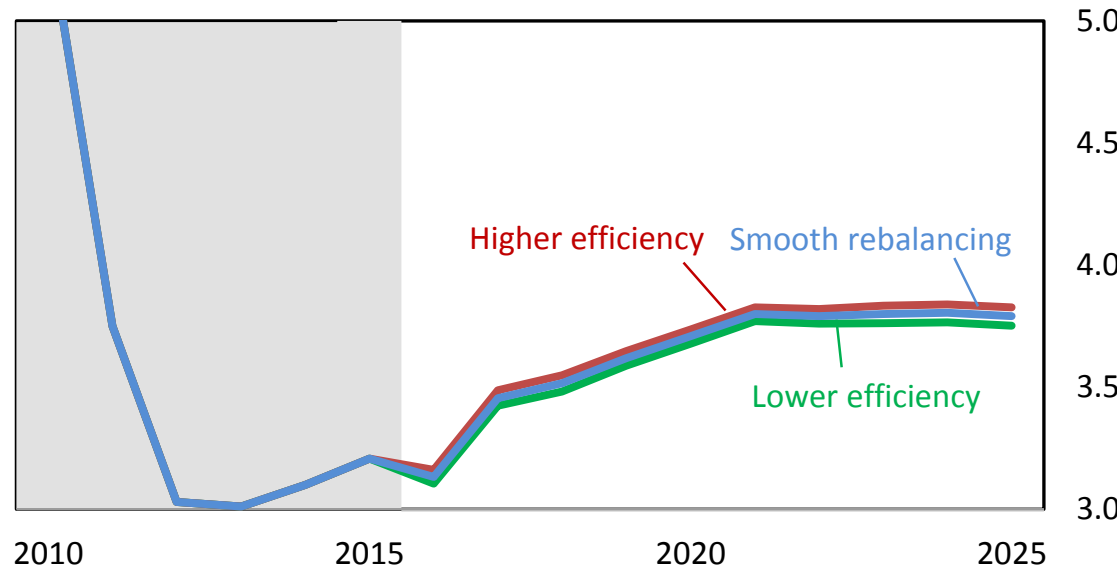

Oil Production

(in millions of barrels per day)

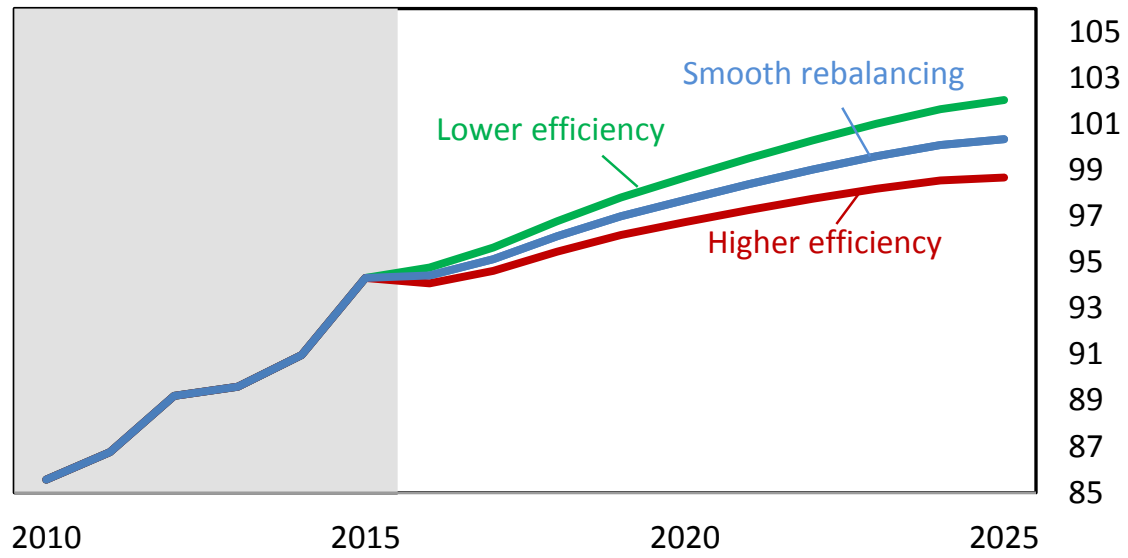

Oil Price

(in 2013 U.S. dollars per barrel)

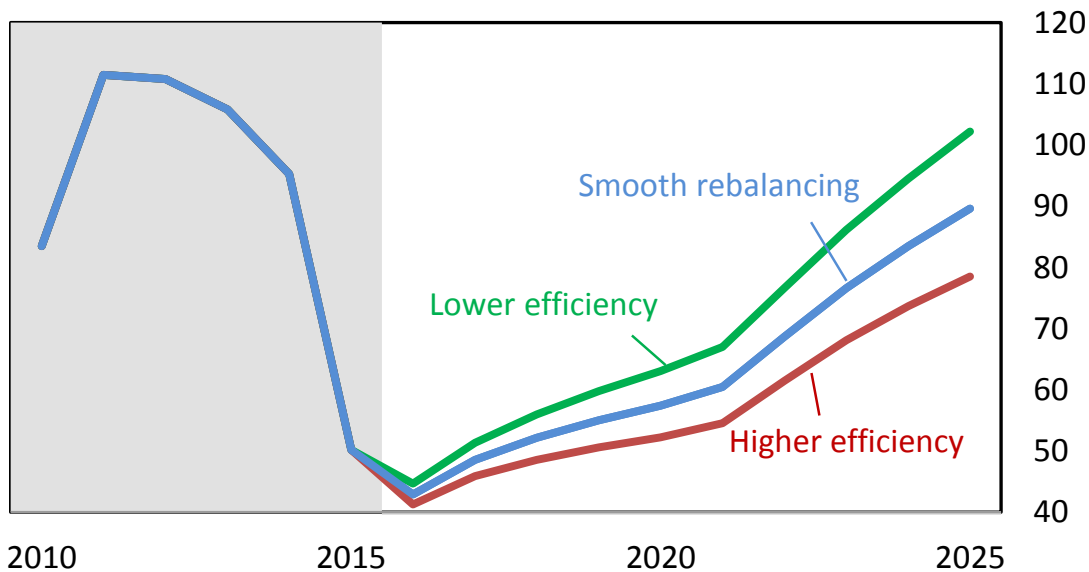

Source: Authors' calculations. 
The scenario shows that a small exogenous change in energy efficiency can have a large and persistent impact on oil prices. The simulations show that a weaker trend in energy efficiency could result in oil prices reaching 100 dollars per barrel. Conversely, larger improvements in energy efficiency could result in oil prices around 80 dollars a barrel in 2025.

\section{Oil Supply Scenarios}

The scenarios in Figure 14 illustrate the effect of an exogenous marginal change in the supply of oil. The pessimistic scenario assumes an exogenous shock that gradually reduces oil supply by 1 million barrels per day by 2025 . That scenario relates, for example, to event such as an increase in environmental restrictions on oil extraction that could stem from the nationally determined contributions to reduce greenhouse gas emissions - to limit global warming below 2 degrees Celsius - agreed upon at the COP21 in Paris in 2015. In contrast, the optimistic supply scenario assumes a positive shock to extraction technology or the discovery of new oil fields that contributes an extra 0.4 million barrels of oil per day to oil supply by 2025 . The asymmetry in the size of shocks to supply reflects the stylized fact that it is more difficult to increase oil supply over time than to reduce it.

These scenarios show that moderate exogenous shocks to oil supply can have dramatic effects on the price of oil over time. The negative oil supply shock produces a rise in oil prices to about 110 dollars per barrel by 2025 . In contrast, the positive supply shock does not reduce the price of oil much, owing to its small size. The rise in oil prices in the pessimistic oil supply scenario reduces world GDP growth by about 0.1 percentage points per annum in the years preceding 2025 . 
Figure 14. Oil Supply Scenarios

Oil Production

(in millions of barrels per day)

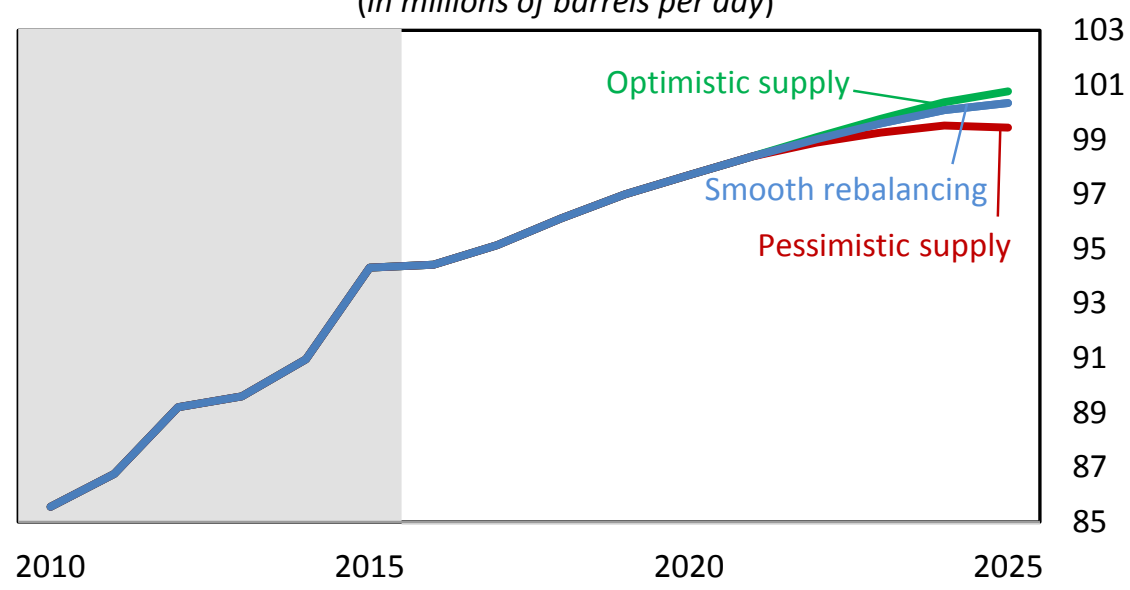

World GDP Growth

(in percent)

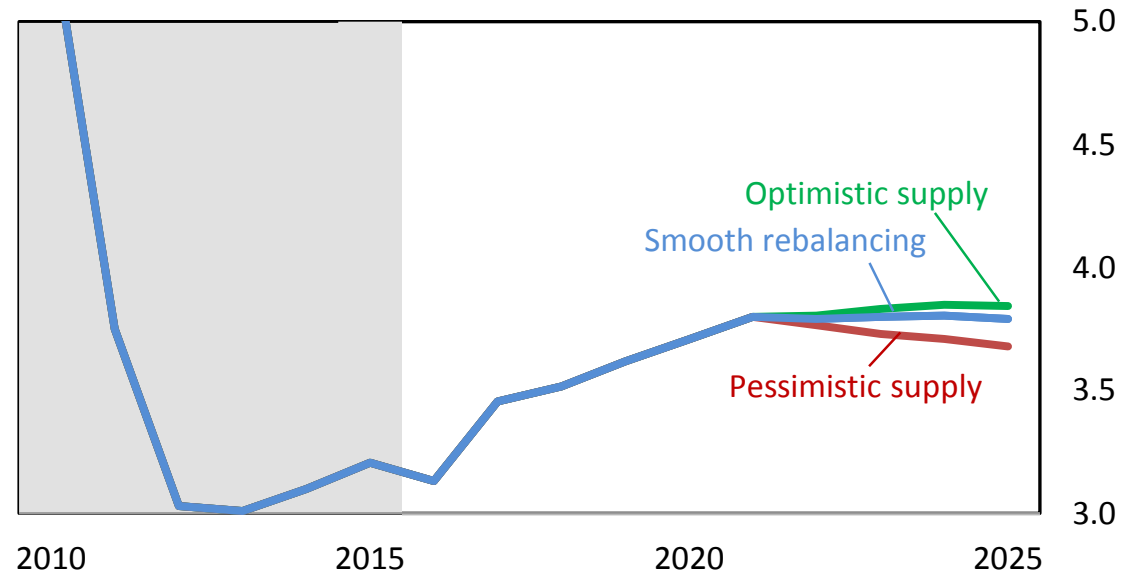

Oil Price

(in 2013 U.S. dollars per barrel)

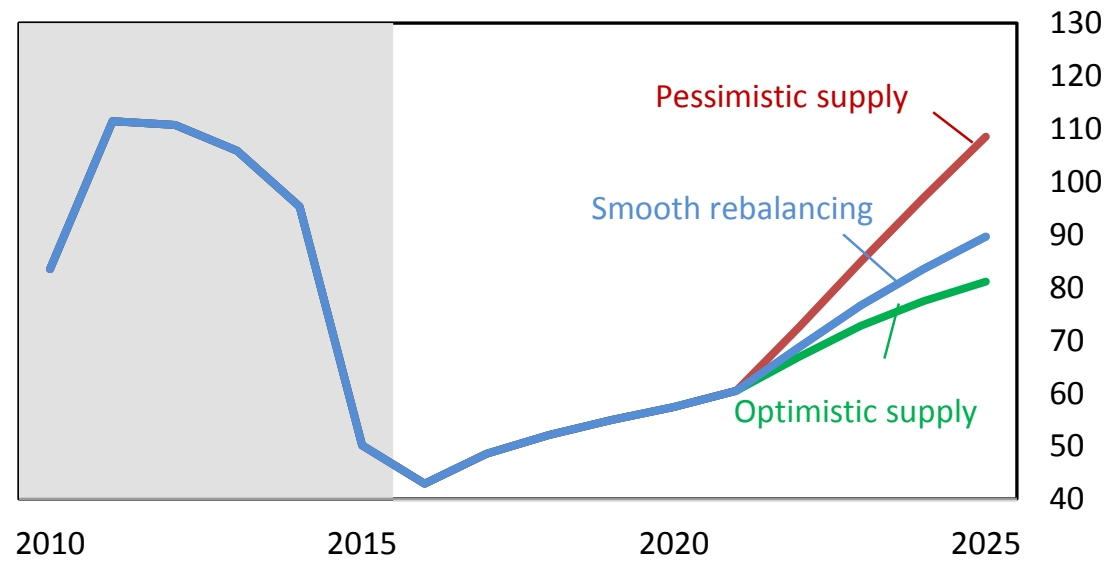

Source: Authors' calculations. 


\section{The Risk of Oil Price Overshooting}

Investment in oil exploration and extraction technologies, as well as in oil use efficiency are sensitive to oil prices - they increase when oil prices are high and decrease when oil prices are low. That sensitivity can give rise to a large overshoot (undershoot) and subsequent cycles in the price of oil and real GDP growth, especially when combined with the long lags between changes in oil prices and shifts in oil supply and demand trends. For example, the decline in investment associated with current low prices of oil may contribute to less supply of oil in the future, and higher oil prices (Figure 15).

Figure 15. Global Upstream Capital Spending 2010-2017 (in billions of 2015 U.S. dollars)

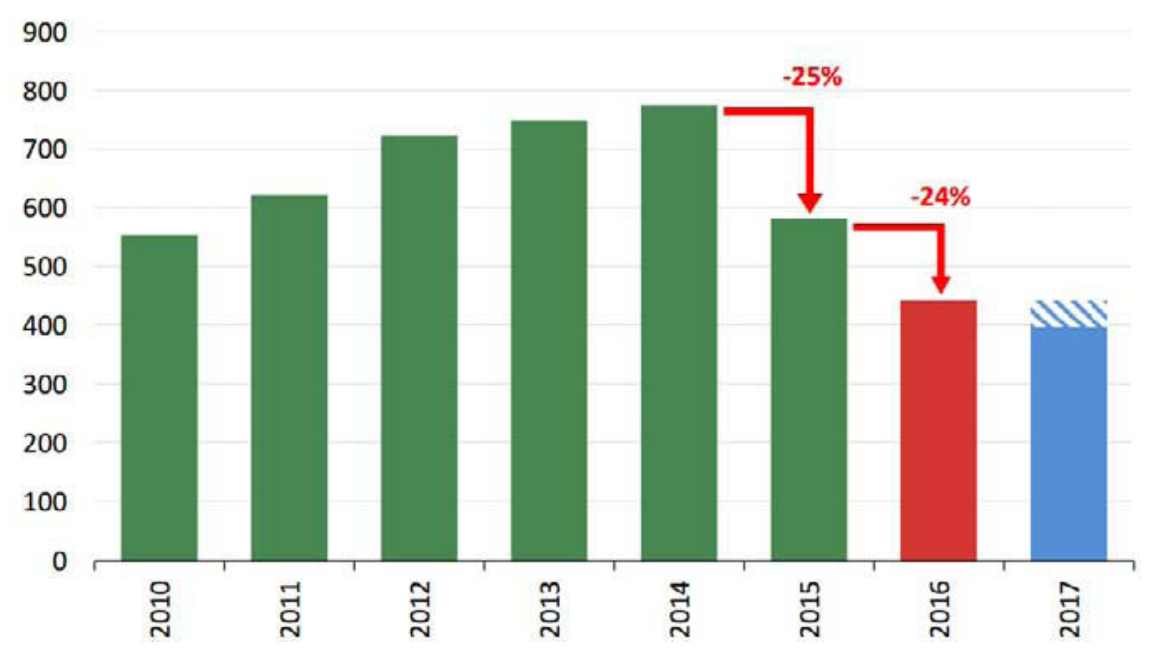

Source: International Energy Agency World Energy Investment 2016.

The risk of oil price overshooting is illustrated in Figure 16. In this scenario, the real price of oil is kept low for 2 additional years compared to the "smooth rebalancing" scenario. The scenario shows that the longer the real price of oil stays low, the greater is the risk of subsequent rise in oil prices. The subsequent rise in oil prices happens because low oil prices have a negative effect on trend oil supply and oil demand, and the negative effect can take many years to materialize fully.

It should be noted that the overshoot in oil prices illustrated in Figure 16 may be overly dramatic as the marginal supplier of oil at current prices is shale oil, and shale oil production may resume faster than the average supply response parameterized in the model. 
Figure 16. The Risk of Oil Price Overshooting

Oil Production

(in millions of barrels per day)

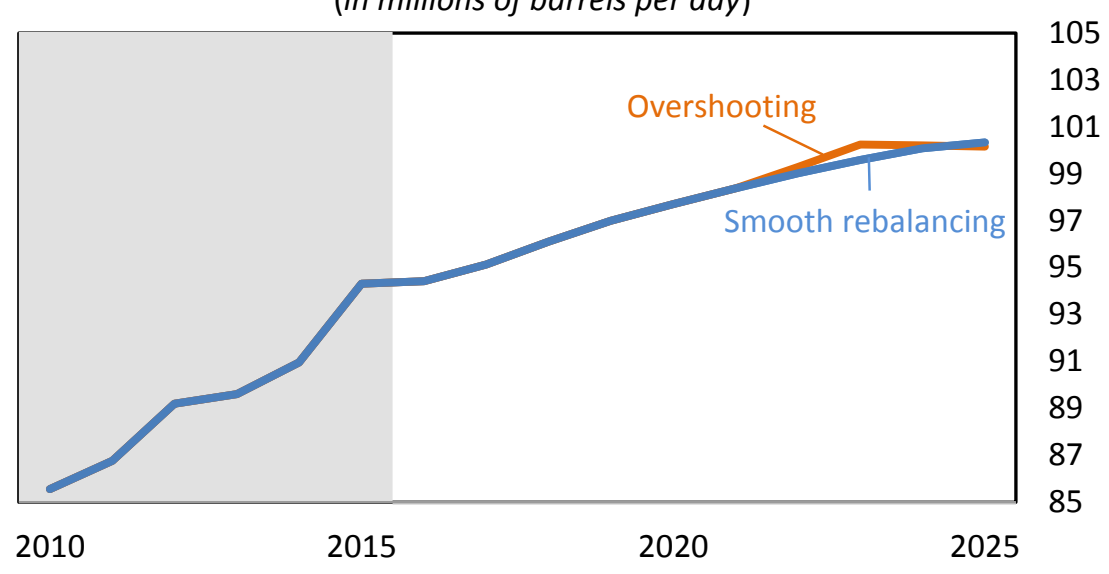

Oil Price

(in 2013 U.S. dollars per barrel)

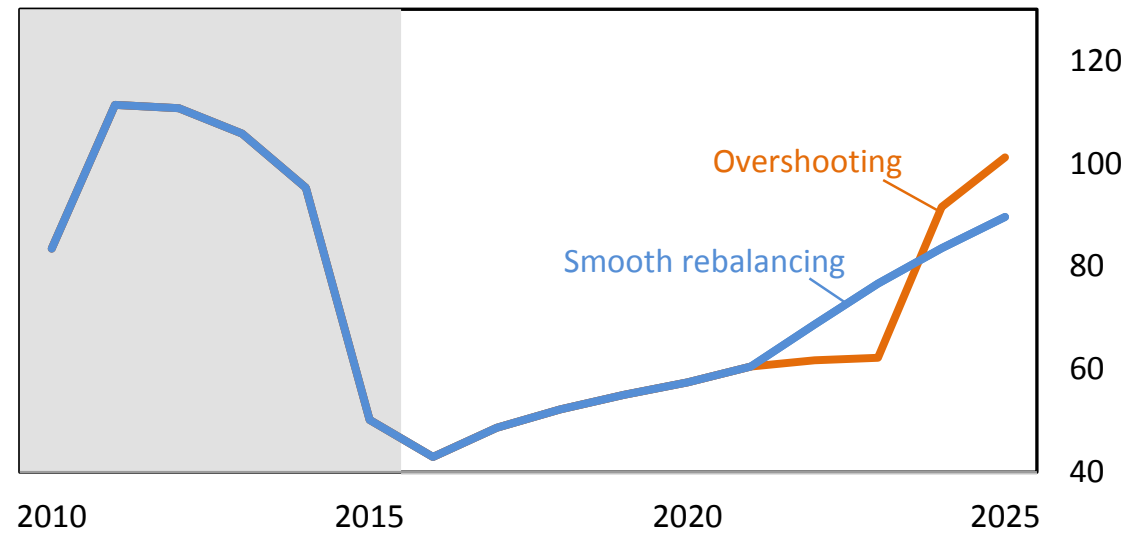

World GDP Growth

(in percent)

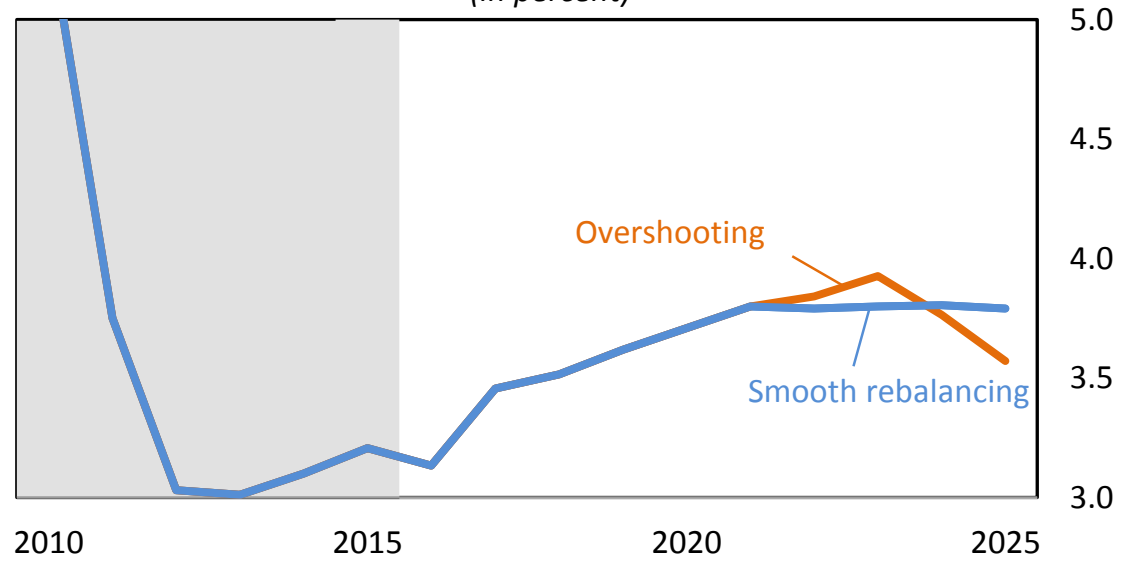

Source: Authors' calculations.

CInternational Monetary Fund. Not for Redistribution 
The forecasts produced by the model are more accurate than benchmark forecasts. Table 4 compares the root mean squared errors from forecasts produced by the model to benchmark forecasts. The benchmark forecasts assume that oil prices follow a random walk process, and take as given the forecasts of oil production from the EIA. The table shows the root mean squared errors at one-to-five-year forecast horizons. In all cases, the forecasts from the model are noticeably more accurate than the benchmark forecasts.

Table 4. Model Root Mean Squared Errors Compared to Benchmark Forecasts

\begin{tabular}{lccccc} 
Data Being Forecast & 1 Year & 2 Year & 3 Year & 4 Year & 5 Year \\
Model Forecast of Real Price of Oil & 20.76 & 27.32 & 31.42 & 32.56 & 32.12 \\
Benchmark Forecast of Real Price of Oil & 24.99 & 42.53 & 54.25 & 68.85 & 82.55 \\
Model Forecast of Oil Production & 1.37 & 1.88 & 2.51 & 2.69 & 2.98 \\
Benchmark Forecast of Oil Production & 1.62 & 2.78 & 3.97 & 4.99 & 5.97 \\
\hline
\end{tabular}

Source: Authors' calculations.

\section{Conclusions}

This paper presented a simple macroeconomic model of the oil market. The model incorporates features of oil supply such as depletion, endogenous oil exploration and extraction, and features of oil demand such as the increase in demand from emerging markets, usage efficiency, and endogenous demand responses. The model provides, inter alia, a useful analytical framework to explore the effects of: a change in world GDP growth; a change in the efficiency of oil usage; and a change in the supply of oil. The model shows that small shocks to oil supply or demand can result in large movements in the price of oil over time. It would not take a large shock for oil prices to return to significantly higher levels, and the long lags between oil price changes and the response of oil supply and demand to those changes can lead to cycles in oil prices in the future.

The overshooting scenario for oil prices is not well-reflected in valuations based on projections of future oil prices. Informational frictions or other elements of market structure or financing constraints may prevent stable capital investment in oil production. An area where progress can be made is the further improvement in the quality and accessibility of information about oil data. Such improvement can help inform producers and consumers alike about ongoing developments in the oil sector in a more timely fashion. In the late 1990s, Energy Ministers identified the lack of transparent and reliable oil statistics as a key contributor to oil price volatility. They subsequently launched the Joint Oil Data Initiative, a coordinated effort between producers and consumers. However, much more needs to be done. More timely and comprehensive data on investment and production prospects could help investors make more informed decisions. Better and more timely information could somewhat reduce uncertainty surrounding medium-term developments, and help break the unduly tight link between contemporaneous oil prices and the level of capital investment. 


\section{References}

Arezki, R. and O. J. Blanchard, 2014, "Seven Questions about the Recent Oil Price Slump," iMFdirect.

Blanchard, O. J. and J. Galí, 2007, "The Macroeconomic Effects of Oil Price Shocks: Why are the 2000s so different from the 1970s?" NBER Chapters, in: International Dimensions of Monetary Policy, pages 373-421.

Blanchard, O. J. and M. Riggi, 2013, "Why Are the 2000s So Different from the 1970s? A Structural Interpretation of Changes in the Macroeconomic Effects of Oil Prices," Journal of the European Economic Association, European Economic Association, vol. 11(5), pages 1032-1052, October.

CEA, 2015a, Explaining the U.S. Petroleum Consumption Surprise, Washington, DC: Council of Economic Advisors.

CEA, 2015b, Economic Report of the President, Washington, DC: Council of Economic Advisors.

Hamilton, J. D., 1983, "Oil and the Macroeconomy since World War II," Journal of Political Economy, 91(2), 228-248.

Hamilton, J. D., 1996, “This is What Happened to the Oil Price-Macroeconomy Relationship," Journal of Monetary Economics, 38(2), 215-220.

Hamilton, J. D., 2003, “What is an Oil Shock?” Journal of Econometrics, 113(2), 363-398.

Kilian, L., 2009, "Not All Oil Price Shocks Are Alike: Disentangling Demand and Supply Shocks in the Crude Oil Market," American Economic Review, 99(3), 1053-1069.

Lippi, F. and A. Nobili, 2012, "Oil and the Macroeconomy: A Quantitative Structural Analysis,” Journal of the European Economic Association, 10(5), 1059-1083.

Obstfeld, M., G. M. Milesi-Ferretti, and R. Arezki, 2016, "Oil Prices and the Global Economy: It's Complicated," iMFdirect (short version) and VoxEU (long version).

Peersman, G. and I. Van Robays, 2012, "Cross-country differences in the effects of oil shocks," Energy Economics, Elsevier, vol. 34(5), pages 1532-1547. 